\title{
Impact of the Nature and Size of the Polymeric Backbone on the Ability of Heterobifunctional Ligands to Mediate Shiga Toxin and Serum Amyloid P Component Ternary Complex Formation
}

\author{
Pavel I. Kitov ${ }^{1}{ }^{*}$, Eugenia Paszkiewicz ${ }^{1}$, Joanna M. Sadowska ${ }^{1}$, Zhicheng Deng ${ }^{2}$, \\ Marya Ahmed ${ }^{2}$, Ravin Narain ${ }^{2}$, Thomas P. Griener ${ }^{3}$, George L. Mulvey ${ }^{3}$, Glen D. Armstrong ${ }^{3}$ \\ and David R. Bundle ${ }^{1, *}$
}

1 Department of Chemistry, Alberta Ingenuity Centre for Carbohydrate Science, University of Alberta, Edmonton AB, Canada T6G 2G2; E-Mails: eugeniap@ualberta.ca (E.P.); joanna.sadowska@ualberta.ca (J.M.S.)

2 Department of Chemical Engineering, University of Alberta, Edmonton AB, Canada; E-Mails: zdeng@ualberta.ca (Z.D.); marya1@ualberta.ca (M.A.); narain@ualberta.ca (R.A.)

3 Department of Microbiology, Immunology, and Infectious Diseases, Alberta Ingenuity Centre for Carbohydrate Science, University of Calgary, Calgary, AB, Canada T2N 4N1;

E-Mails: gmulvey@ucalgary.ca (G.L.M.); armstrong@ucalgary.ca (G.D.A.)

* Authors to whom correspondence should be addressed; E-Mails: pkitov@ualberta.ca (P.I.K.); dave.bundle@ualberta.ca (D.R.B.); Tel.: +1-780-492-8820 (P.I.K.); +1-780-492-8808 (D.R.B.).

Received: 14 July 2011; in revised form: 16 August 2011 / Accepted: 19 August 2011 / Published: 25 August 2011

\begin{abstract}
Inhibition of $\mathrm{AB}_{5}$-type bacterial toxins can be achieved by heterobifunctional ligands (BAITs) that mediate assembly of supramolecular complexes involving the toxin's pentameric cell membrane-binding subunit and an endogenous protein, serum amyloid $\mathrm{P}$ component, of the innate immune system. Effective in vivo protection from Shiga toxin Type 1 (Stx1) is achieved by polymer-bound, heterobifunctional inhibitors-adaptors (PolyBAITs), which exhibit prolonged half-life in circulation and by mediating formation of face-to-face $\mathrm{SAP}-\mathrm{AB}_{5}$ complexes, block receptor recognition sites and redirect toxins to the spleen and liver for degradation. Direct correlation between solid-phase activity and protective dose of PolyBAITs both in the cytotoxicity assay and in vivo indicate that the mechanism of protection from intoxication is inhibition of toxin binding to the host cell membrane. The polymeric scaffold influences the activity not only by clustering active binding fragments but also by sterically interfering with the supramolecular complex
\end{abstract}


assembly. Thus, inhibitors based on $\mathrm{N}$-(2-hydroxypropyl) methacrylamide (HPMA) show significantly lower activity than polyacrylamide-based analogs. The detrimental steric effect can partially be alleviated by extending the length of the spacer, which separates pendant ligand from the backbone, as well as extending the spacer, which spans the distance between binding moieties within each heterobifunctional ligand. Herein we report that polymer size and payload of the active ligand had moderate effects on the inhibitor's activity.

Keywords: E. coli O157:H7; multivalent inhibitors; $\mathrm{P}^{\mathrm{k}}$-trisaccharide; $\mathrm{Gb}_{3}$

\section{Introduction}

Enteric infections with Shigatoxigenic Escherichia coli (STEC), particularly the O157:H7 strain, is the leading cause of hemolytic-uremic syndrome (HUS) in industrialized countries [1]. HUS is a term for an acute form of renal disease that commonly manifests itself as hemolytic anemia, acute renal failure, thrombocytopenia, and central nervous system impairment. Most symptoms of HUS are mediated by exotoxins called Shiga toxins (Stx) that enter the circulation through an eroded intestinal epithelium and are rapidly absorbed in target tissues such as the kidney and the central nervous system, as well as inflicting serious systemic damage [2].

Shiga toxins are a group of closely related bacterial toxins that are serologically differentiated into two types, Stx 1 and Stx 2 with $\sim 60 \%$ homology, and a number of variants differing by just a few amino acids. Stx are potent cytotoxins with ribosomal deadenylase activity that cause cell death through activating pro-apoptotic signals by inducing an endoplasmic reticulum stress response in susceptible tissues. The Stx host cell receptor is the $\mathrm{P}^{\mathrm{k}}$ trisaccharide head group $[\mathrm{Gal}(\alpha 1-4) \mathrm{Gal}(\beta 1-4) \mathrm{Glc}(\beta 1-O)]$ of the glycolipid, $\mathrm{Gb}_{3}$.

Since outbreaks of STEC infections can be contained by sanitary measures and by monitoring the water and food supply the incidence of HUS is relatively low, hence, immunization of the general population cannot be justified given the safety constraints of a vaccine. Treatment of infected patients is needed to prevent progression of the infection to HUS. However, despite tremendous advances in understanding STEC pathogenesis the clinical options for treatment remain limited to mainly supportive strategies. Antibiotics can stimulate further Stx production and, therefore, are presently not recommended [3,4]. Most notable, an earlier attempt to develop a Stx-targeting therapy for STEC-induced HUS was an orally administered indigestible affinity agent, Synsorb- $\mathrm{P}^{\mathrm{k}}$, designed to sequester Stx in the intestine before Stx entered the circulation. Unfortunately, this approach failed to demonstrate significant efficacy in a Phase 2 clinical trial [5]. Recently, passive immunization with monoclonal antibodies raised against Stx1 [6] and Stx2 [7] has been shown to be effective in animal models and a humanized monoclonal antibody urtoxazumab against Shiga-like toxin 2 is undergoing clinical trials [8]. Compounds that affect intracellular trafficking of Stx have shown efficacy in vitro and in vivo $[9,10]$. This suggests that a soluble injectable antitoxin agent might be able to prevent or lessen the severity of HUS. 
Recently, we demonstrated the in vivo efficacy of a polyacrylamide-based pre-ordered heterobifunctional ligand named PolyBAIT that induces the formation of face-to-face complexes between the Shiga toxin pentameric B-subunit $\left(\operatorname{Stx} 1-B_{5}\right)$ and an endogenous human serum protein, serum amyloid P component (SAP, Figure 1), thereby protecting mice from intoxication by Stx1 [11]. SAP is a serum circulating pentraxin, a pentameric doughnut-shaped protein, that topologically matches the pentameric carbohydrate binding subunit of Stx1. The ligand-mediated ternary complex formation with SAP inhibits the cell-recognition domain of Stx1 and facilitates safe disposal of the complex in the liver [11].

Figure 1. Molecular model of supramolecular complexes between Stx 1 and SAP mediated by PolyBAIT. SAP: Green surface; Stx1-B 5 subunit: Blue surface; Stx1-A subunit: Pink surface. Left panel: PolyBAIT with fused binding fragments; Right panel: PolyBAIT with separate binding fragments. Polymer atoms omitted for clarity. Molecular representation was rendered with PyMol (www.pymol.org).

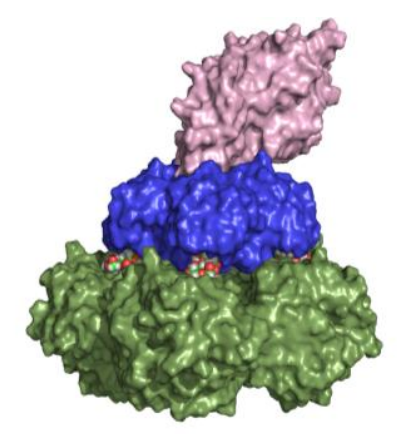

Fused PolyBAIT

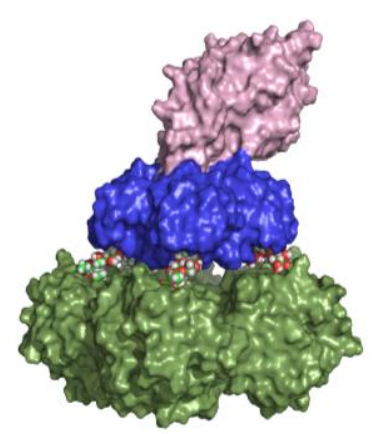

Separate PolyBAIT
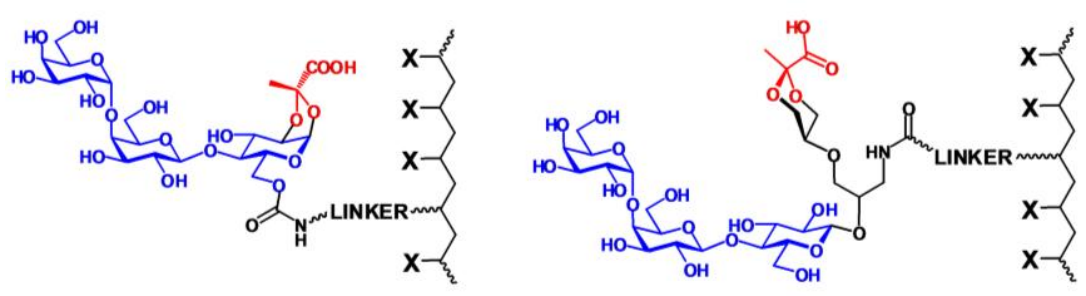

Blue: Stx-binding fragment; Red: SAP-binding fragment; $\mathbf{X}$ : polymer side chain

Herein we report the synthesis and activity evaluation of a series of glycoconjugates containing a ligand with dual specificity for Stx 1 and SAP linked to the polymeric scaffolds, polyacrylamide and $N$-(2-hydroxypropyl) methacrylamide (HPMA). We employ narrow molecular weight range polymeric scaffolds obtained by RAFT polymerization in order to investigate the impact of the nature and the size of the polymeric backbone and the linker on the activities of the polymeric heterobifunctional ligands. 


\section{Materials and Methods}

\subsection{Synthesis of Heterobifunctional Inhibitors}

Commercially available reagents were used as supplied without further purification. Evaporation and concentration in vacuo was conducted under water-aspirator pressure. All solution-phase reactions were carried out under nitrogen atmosphere. Reactions were monitored by analytical thin-layer chromatography (TLC) with pre-coated silica gel $60 \mathrm{~F}_{254}$ glass plate (Merck). Plates were visualized under UV light or stained by treatment with either cerium ammonium molybdate solution or $5 \%$ sulfuric acid in ethanol followed by heating at $180{ }^{\circ} \mathrm{C}$. Purification of products was conducted by column chromatography using silica gel SiliaFlashF60 (40-63 $\mu \mathrm{m}, 60 \AA$ A) from SiliCycle ${ }^{\circledR}$ Inc. IR data were recorded on a Nic-Plan IR Microscope (solid film); only signals corresponding to functional groups indicative to the structure are reported. NMR spectra were recorded at 500 or $600 \mathrm{MHz}$, at $27{ }^{\circ} \mathrm{C}$ in $\mathrm{CDCl}_{3}$ or $\mathrm{D}_{2} \mathrm{O}$. Chemical shifts are referenced to residual solvent $\left(\mathrm{CDCl}_{3}\right)$ at 7.24 p.p.m. for ${ }^{1} \mathrm{H}$ and 77.0 p.p.m. for ${ }^{13} \mathrm{C}$ and relative to $0.1 \%$ external acetone at 2.225 p.p.m. for ${ }^{1} \mathrm{H}$ for solutions in $\mathrm{D}_{2} \mathrm{O}$. Electrospray ionization mass spectra were recorded on a Micromass Zabspec TOF-mass spectrometer.

Prop-2-ynyl 2-(2-(2-t-butyloxycarbonylaminoethoxy)ethoxy)ethylcarbamate (1). To a solution of tert-butyl 2-[2-(2-aminoethoxy)ethoxy]ethylcarbamate [12] $(698 \mathrm{mg}, 2.81 \mathrm{mmol})$ in dry DCM ( $3 \mathrm{~mL})$ at $-78{ }^{\circ} \mathrm{C}$ triethylamine $(0.85 \mathrm{~g}, 8.4 \mathrm{mmol})$ was added followed by propargyl chloroformate (522 mg, $4.4 \mathrm{mmol}$ ). The mixture was allowed to warm to room temperature and then stirred for $1.5 \mathrm{~h}$. The mixture was diluted with DCM, washed with brine, concentrated and chromatographed on silica gel using hexane-acetone (7:3) to yield product 1 as a clear syrup (689 mg, 74\%); ${ }^{1} \mathrm{H}-\mathrm{NMR}\left(\mathrm{CDCl}_{3}\right)$ $\delta: 5.63$ (bs, $1 \mathrm{H}, \mathrm{NH}), 5.26$ (bs, $1 \mathrm{H}, \mathrm{NH}), 4.93$ (d, $\left.2 \mathrm{H}, J 2.3 \mathrm{~Hz}, \mathrm{CH}_{2}\right), 3.88-3.86\left(\mathrm{~m}, 4 \mathrm{H}, \mathrm{OCH}_{2}\right)$, 3.83-3.76 (m, $\left.4 \mathrm{H}, \mathrm{OCH}_{2}\right), 3.66-3.60\left(\mathrm{~m}, 2 \mathrm{H}, \mathrm{NCH}_{2}\right), 3.57-3.52\left(\mathrm{~m}, 2 \mathrm{H}, \mathrm{NCH}_{2}\right), 2.70(\mathrm{t}, 1 \mathrm{H}, \mathrm{CH})$, $1.70\left(\mathrm{~s}, 9 \mathrm{H} t \mathrm{Bu}\right.$ ); ESI HRMS: $m / z$ : calcd for $\mathrm{C}_{15} \mathrm{H}_{26} \mathrm{~N}_{2} \mathrm{O}_{6} \mathrm{Na}$ : 353.1683 ; found: $353.1681[\mathrm{M}+\mathrm{Na}]^{+}$.

\section{3-O-Acetyl-6-O-(10-oxo-3,6,11-trioxa-9-azatetradec-13-ynyl)carbamoyl-4-O-(2,3,4,6-tetra- $O$ -} acetyl- $\beta$-D-galactopyranosyl)-1,2- $O$-[(S)-1-(methoxycarbonyl)ethylidene]- $\alpha$-D-glucopyranoside (3). Alkyne 1 (545 mg, $1.65 \mathrm{mmol})$ was dissolved in TFA (1.6 mL) and left at room temperature for $1 \mathrm{~h}$. The mixture was concentrated, treated with $\mathrm{Et}_{3} \mathrm{~N}$ and concentrated again then 3-O-acetyl-6- $O$-(4-nitrophenyloxycarbonyl)-4- $O$-(2,3,4,6-tetra- $O$-acetyl- $\beta$-D-galactopyranosyl)-1,2- $O$ [(S)-1-(methoxycarbonyl) ethylidene]- $\alpha$-D-glucopyranoside 2 [11] (886 mg, $1.105 \mathrm{mmol}$ ) was added. The mixture was dissolved in dry DCM $(10 \mathrm{~mL})$ and triethylamine $(310 \mu \mathrm{L}, 2.21 \mathrm{mmol})$ was added. The reaction mixture was stirred at room temperature for $2 \mathrm{~h}$. The mixture was concentrated and chromatographed on silica gel using hexane-acetone $(2: 1$ to $1: 1)$ to provide the title compound 3 as a white foam $(0.93 \mathrm{~g}, 94 \%)$; ${ }^{1} \mathrm{H}-\mathrm{NMR}\left(\mathrm{CDCl}_{3}\right) \delta: 5.76\left(\mathrm{~d}, 1 \mathrm{H}, J_{1,2} 5.13 \mathrm{~Hz}, \mathrm{H}-1\right) 1.53-1.52(\mathrm{~m}, 1 \mathrm{H}$, H-3), 5.46-5.40 (m, $1 \mathrm{H}, \mathrm{NH}), 5.38$ (dd, $\left.1 \mathrm{H}, \mathrm{H} J_{3^{\prime}, 4^{\prime}} 3.5 \mathrm{~Hz}, J_{4^{\prime}, 5^{\prime}} 0.7 \mathrm{~Hz}, \mathrm{H}-4^{\prime}\right), 5.18$ (dd, $1 \mathrm{H}, J_{1^{\prime}, 2^{\prime}}$ $\left.7.0 \mathrm{~Hz}, J_{2^{\prime}, 3^{\prime}} 10.4 \mathrm{~Hz}, \mathrm{H}-2^{\prime}\right), 5.01$ (dd, $\left.1 \mathrm{H}, \mathrm{H}-3^{\prime}\right), 4.68$ (d, $2 \mathrm{H}, J 2.2 \mathrm{~Hz}, \mathrm{CH}_{2}$ ), 4.62 (d, $\left.1 \mathrm{H}, \mathrm{H}-1^{\prime}\right)$, 4.36-4.33 (m, $1 \mathrm{H}, \mathrm{H}-2$ ), 4.24 (dd, $\left.1 \mathrm{H}, J_{5,6 \mathrm{a}} 2.2 \mathrm{~Hz}, J_{6 \mathrm{a}, 6 \mathrm{~b}} 11.7 \mathrm{~Hz}, \mathrm{H}-6 \mathrm{a}\right), 4.18-4.10$ (m, $3 \mathrm{H}, \mathrm{H}-6 \mathrm{~b}$, H-6'a, H-6'b), 3.96-3.93 (m, 1 H, H-5'), 3.92-3.88 (m, $1 \mathrm{H}, \mathrm{H}-5), 3.76$ (s, $\left.3 \mathrm{H}, \mathrm{OCH}_{3}\right)$, 3.64-3.54 (m, 8 H, $\left.\mathrm{OCH}_{2}\right), 3.42-3.36\left(\mathrm{~m}, 4 \mathrm{H}, \mathrm{NCH}_{2}\right), 2.48(\mathrm{t}, 1 \mathrm{H}, \mathrm{CH}), 2.18,2.10,2.031 .98(5 \mathrm{~s}, 15$ $\mathrm{H}, 5 \mathrm{OAc}$ ), $1.76\left(\mathrm{~s}, 3 \mathrm{H}, \mathrm{CH}_{3}\right.$ ); ESI HRMS: $m / z$ : calcd for $\mathrm{C}_{37} \mathrm{H}_{52} \mathrm{~N}_{2} \mathrm{O}_{23} \mathrm{Na}$ : 915.2853; found 
915.2846 [M $+\mathrm{Na}]^{+}$.

\section{1,2- $O$-[(S)-1-(carboxy)ethylidene]-4- $O$-( $\beta$-D-galactopyranosyl)-6- $O$-(10-oxo-3,6,11-trioxa-9-}

azatetradec-13-ynyl)carbamoyl- $\alpha$-D-glucopyranoside (4). Disaccharide 3 (480 mg, $0.537 \mathrm{mmol}$ ) was dissolved in dry methanol $(4 \mathrm{~mL})$ and $1 \mathrm{M} \mathrm{NaOMe}(0.54 \mathrm{~mL})$ was added. The solution was stirred at room temperature for $16 \mathrm{~h}$. The mixture was concentrated and dissolved in water. After $0.5 \mathrm{~h}$ TLC indicated that hydrolysis of the methyl ester was complete. The mixture was neutralized with $5 \mathrm{M}$ acidic acid and lyophilized to provide the product 4 as white foam $(387 \mathrm{mg}, 94 \%) .{ }^{1} \mathrm{H}-\mathrm{NMR}\left(\mathrm{D}_{2} \mathrm{O}\right)$ $\delta: 5.62\left(\mathrm{~d}, 1 \mathrm{H}, J_{1,2} 5.0 \mathrm{~Hz}, \mathrm{H}-1\right), 4.67\left(\mathrm{~d}, 1 \mathrm{H}, J 2.1 \mathrm{~Hz}, \mathrm{CH}_{2}\right), 4.44\left(\mathrm{~d}, 1 \mathrm{H}, J_{1^{\prime}, 2^{\prime}} 7.8 \mathrm{~Hz}, \mathrm{H}-1^{\prime}\right)$, 4.41-4.37 (m, 2 H, $\left.J_{2,3} 4.1 \mathrm{~Hz}, J_{6 \mathrm{a}, 6 \mathrm{~b}} 11.9 \mathrm{~Hz}, \mathrm{H}-3, \mathrm{H}-6 \mathrm{a}\right), 4.24$ (dd, 1 H, $J_{5,6 \mathrm{~b}} 5.2 \mathrm{~Hz}, \mathrm{H}-6 \mathrm{~b}$ ), 4.18 (dd, 1 H, H-2), 4.06-4.01 (m, 1 H, H-5), 3.91 (d, 1 H, J J',4' 3.4 Hz, H-4'), 3.82-3.60 (m, 13 H, H-4, H-3', H-5', H-6'a, H-6'b, $4 \times \mathrm{OCH}_{2}$ ), 3.55 (dd, 1 H, H-2'), 3.36-3.32 (m, 4 H, $2 \times \mathrm{NCH}_{2}$ ), 2.9 (t, $\left.1 \mathrm{H}, \mathrm{CH}\right), 1.64$ (s, $\left.3 \mathrm{H}, \mathrm{CH}_{3}\right)$. ESI HRMS: $m / z$ : calcd for $\mathrm{C}_{26} \mathrm{H}_{39} \mathrm{~N}_{2} \mathrm{O}_{18}$ : 667.2203; found 667.2205 [M - H] ${ }^{-}$.

\section{1,2-O-[(S)-1-(carboxy)ethylidene]-4- $O$-[4- $O$ - $(\alpha$-D-galactopyranosyl)- $\beta$-D-galactopyranosyl]-6-} $\boldsymbol{O}$-(10-oxo-3,6,11-trioxa-9-azatetradec-13-ynyl)carbamoyl- $\alpha$-D-glucopyranoside (5). Compound 4 (379 $\mathrm{mg}, 0.537 \mathrm{mmol}$ ) was dissolved in water $(5.34 \mathrm{~mL})$ and the $\mathrm{pH}$ was adjusted to 7.5 by addition of solid $\mathrm{NaHCO}_{3}$. Then $1 \mathrm{M}$ HEPES buffer ( $\mathrm{pH}: 8,3.2 \mathrm{~mL}$ ) was added followed by $0.4 \mathrm{M}$ DTT solution $(500 \mu \mathrm{L})$ and alkaline phosphatase $(1 \mathrm{U} / \mu \mathrm{L}, 50 \mu \mathrm{L}$, Sigma). UDP-glucose (578 mg, $0.849 \mathrm{mmol})$ was dissolved in the reaction mixture and the fusion enzyme GalT/UDP-4'-epimerase [21] (950 $\mu \mathrm{L})$ was added. The reaction mixture was incubated at $37{ }^{\circ} \mathrm{C}$. After $24 \mathrm{~h}$ the reaction mixture was treated with Dowex $\mathrm{H}^{+}$resin, filtered and freeze-dried. NMR of the crude product confirmed the reaction was complete. The mixture was purified on silica gel using DCM-methanol (2:1 with $2 \%$ acetic acid) to afford after 2 passages pure trisaccharide $5(270 \mathrm{mg}, 61 \%)$. Impure fractions were further purified on HPLC $\left(\mathrm{C}_{18}\right)$ using water (with $0.1 \%$ TFA)-acetonitrile to yield an additional amount of trisaccharide (51 mg, 11\%); ${ }^{1} \mathrm{H}-\mathrm{NMR}\left(\mathrm{D}_{2} \mathrm{O}\right) \delta: 5.64$ (d, $\left.1 \mathrm{H}, J_{1,2} 5.0 \mathrm{~Hz}, \mathrm{H}-1\right), 4.94$ (d, $\left.1 \mathrm{H}, J_{1 ", 2 "} 4.0 \mathrm{~Hz}, \mathrm{H}-1 "\right), 4.67$ (d, $2 \mathrm{H}, J 2.2 \mathrm{~Hz}, \mathrm{CH}_{2}$ ), 4.51 (d, $\left.1 \mathrm{H}, J_{1^{\prime}, 2^{\prime}} 7.8 \mathrm{~Hz}, \mathrm{H}-1^{\prime}\right), 4.41-4.33$ (m, $\left.3 \mathrm{H}, \mathrm{H}-3, \mathrm{H}-6 \mathrm{a}, \mathrm{H}-5 "\right)$, 4.28-4.21 (m, 2 H, H-2, H-6b), 4.04-4.00 (m, 3 H, H-5, H-4', H-4"), 3.94-3.90 (m, 2 H, H-6'a, H-3"), 3.85-3.75 (m, 4 H, H-4, H-5', H-6'b, H-2"), 3.72-3.66 (m, 7 H, H-3', H-6"a, H-6"b, $2 \times \mathrm{OCH}_{2}$ ), 3.63-3.56 (m, 5 H, H-2', $\left.2 \times \mathrm{OCH}_{2}\right), 3.34-3.32\left(\mathrm{~m}, 4 \mathrm{H}, 2 \times \mathrm{NCH}_{2}\right), 2.90(\mathrm{t}, 1 \mathrm{H}, \mathrm{CH}), 1.69(\mathrm{~s}, 3 \mathrm{H}$, $\mathrm{CH}_{3}$ ). ESI HRMS: $m / z$ : calcd for $\mathrm{C}_{32} \mathrm{H}_{50} \mathrm{~N}_{2} \mathrm{O}_{23}: 829.2732$; found: $829.2734[\mathrm{M}-\mathrm{H}]^{-}$.

$(R, S)-5$-(3-azido-2-hydroxypropoxy)- $N, N, 2$-trimethyl-1,3-dioxane-2-carboxamide (7). Epoxide 6 [13] (4.595 g, $18.734 \mathrm{mmol})$ was dissolved in dry DMF (20 mL) then sodium azide (3.66 g, $56.2 \mathrm{mmol}$ ) and ammonium chloride $(3.01 \mathrm{~g}, 56.2 \mathrm{mmol})$ were added and the mixture was stirred for $5 \mathrm{~h}$ at $50 \mathrm{C}$ then overnight at room temperature. Water $(100 \mathrm{~mL})$ was added and the mixture was extracted with ethyl acetate $(3 \times 50 \mathrm{~mL})$. Combined organic layers were washed with saturated $\mathrm{NH}_{4} \mathrm{Cl}$ and brine, then dried with $\mathrm{MgSO}_{4}$, filtered and concentrated. The residue was purified on silica gel using hexane-acetone (3:1) to provide the title compound 7 as a clear syrup $(2.9 \mathrm{~g}, 54 \%)$. ${ }^{1} \mathrm{H}-\mathrm{NMR}$

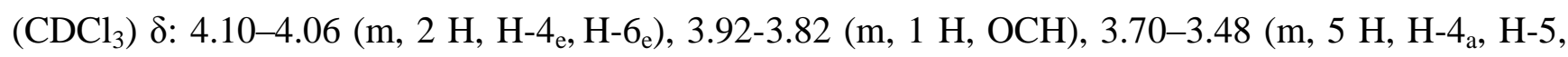
H-6 $\left.{ }_{\mathrm{a}}, \mathrm{OCH}_{2}\right), 3.40-3.28\left(\mathrm{~m}, 2 \mathrm{H}, \mathrm{NCH}_{2}\right), 3.24$ and $3.02\left(2 \mathrm{~s}, 6 \mathrm{H}, \mathrm{NMe}_{2}\right), 1.52\left(\mathrm{~s}, 3 \mathrm{H}, \mathrm{CH}_{3}\right)$; ESI HRMS: $m / z$ : calcd for $\mathrm{C}_{11} \mathrm{H}_{20} \mathrm{~N}_{4} \mathrm{O}_{5} \mathrm{Na}$ : 311.1326; found: $311.1329[\mathrm{M}+\mathrm{Na}]^{+}$.

$(R, S)-5$ - $\{3$-azido-2-[2,3,6-tri- $O$-acetyl-4-(2,3,4,6-tetra- $O$-acetyl- $\beta$-D-galactopyranosyl)- $\beta$-Dglucopyranosyloxy]propoxy\}- $N, N, 2$-trimethyl-1,3-dioxane-2-carboxamide (9). Azide 7 (1.05 g, $3.64 \mathrm{mmol})$ and lactosyl trichloroacetimidate 8 [14] (3.37 g, $4.32 \mathrm{mmol})$ were dried together under 
vacuum overnight then dissolved in dry DCM $(30 \mathrm{~mL})$ and powdered molecular sieves $4 \AA$ were added and the mixture was stirred under argon for $0.5 \mathrm{~h}$ and cooled to $0{ }^{\circ} \mathrm{C}$. TMSOTf $(50 \mu \mathrm{L}, 61 \mathrm{mg}$, $0.27 \mathrm{mmol}$ ) was added slowly then the ice bath was removed and stirring continued at room temperature. After 40 min the mixture was neutralized with a drop of $\mathrm{Et}_{3} \mathrm{~N}$, filtered through celite, concentrated and chromatographed on silica gel using hexane-acetone (3:1 to 3:2) to provide the title product 9 as white foam $(2.4 \mathrm{~g}, 69 \%) ;{ }^{1} \mathrm{H}-\mathrm{NMR}\left(\mathrm{CDCl}_{3}\right) \delta: 5.36-5.34\left(\mathrm{~m}, 1 \mathrm{H}, J_{3^{\prime}, 4^{\prime}} 3.4 \mathrm{~Hz}, \mathrm{H}-4^{\prime}\right)$, 5.20-5.16 (m, $1 \mathrm{H}, \mathrm{H}-3), 5.13-5.08$ (m, $\left.1 \mathrm{H}, J_{1^{\prime}, 2^{\prime}} 7.8 \mathrm{~Hz}, \mathrm{H}-2^{\prime}\right), 4.98-4.94$ (m, $\left.1 \mathrm{H}, \mathrm{H}-3^{\prime}\right), 4.90-4.84$ (m, $\left.1 \mathrm{H}, J_{1,2} 7.9 \mathrm{~Hz}, \mathrm{H}-2\right), 4.63$ (d, $\left.1 \mathrm{H}, \mathrm{H}-1\right), 4.60-4.56$ (m, $\left.1 \mathrm{H}, \mathrm{H}-6 \mathrm{a}\right), 4.52-4.49$ (m, $\left.1 \mathrm{H}, \mathrm{H}-1^{\prime}\right)$, 4.15-4.02 (m, 5 H, H-4e $\mathrm{e}_{\text {pyr }}$, H-6e $\mathrm{e}_{\mathrm{pyr}}$, H-6b, H-6a', H-6b'), 3.90-3.85 (m, 1 H, H-5'), 3.83-3.68 (m, 2 H, $\mathrm{H}-4, \mathrm{CH}), 3.65-3.44$ (m, $\left.6 \mathrm{H}, \mathrm{H}-5, \mathrm{H}-4 \mathrm{a}_{\mathrm{pyr}}, \mathrm{H}-5_{\mathrm{pyr}}, \mathrm{H}-6 \mathrm{a}_{\mathrm{pyr}}, \mathrm{OCH}_{2}\right), 3.41-3.35$ and 3.30-3.22 (2 m, 2 $\left.\mathrm{H}, \mathrm{NCH}_{2}\right), 3.22$ and $3.02\left(2 \mathrm{~s}, 6 \mathrm{H}, \mathrm{NMe}_{2}\right), 2.16-1.97(\mathrm{~ms}, 21 \mathrm{H}, 7 \times \mathrm{OAc}), 1.50\left(\mathrm{~s}, 3 \mathrm{H}, \mathrm{CH}_{3}\right)$. ESI HRMS: $m / z$ : calcd for $\mathrm{C}_{47} \mathrm{H}_{54} \mathrm{~N}_{4} \mathrm{O}_{22} \mathrm{Na}$ : 929.3; found: $929.3[\mathrm{M}+\mathrm{Na}]^{+}$.

$(R, S)-5$ - $\{3$-acetamido-2-[2,3,6-tri- $O$-acetyl-4-(2,3,4,6-tetra- $O$-acetyl- $\beta$-D-galactopyranosyl)- $\beta$-Dglucopyranosyloxy]propoxy $\}-N, N, 2$-trimethyl-1,3-dioxane-2-carboxamide (10). To a solution of azide 9 (945 mg, $1.04 \mathrm{mmol})$ in dry THF (19 mL) triphenylphosphine (423 mg, $1.6 \mathrm{mmol}$ ) was added and the mixture was stirred at $65^{\circ} \mathrm{C}$ for $6 \mathrm{~h}$ then water $(2.5 \mathrm{~mL})$ was added and the mixture was stirred at $65{ }^{\circ} \mathrm{C}$ for $6.5 \mathrm{~h}$, then concentrated, co-evaporated with toluene and dried under vacuum. The residue was dissolved in pyridine $(20 \mathrm{~mL})$ and acetic anhydride $(10 \mathrm{~mL})$ was added then the mixture was left at room temperature overnight. The mixture was concentrated, co-evaporated with toluene and the residue was chromatographed on silica gel using hexane-acetone (1:1) to provide $N$-acetate 10 as a white foam $(635 \mathrm{mg} ; 65 \%) ;{ }^{1} \mathrm{H}$-NMR $\left(\mathrm{CDCl}_{3}\right) \delta: 6.07(\mathrm{t}, 0.45 \mathrm{H}, J 5.5 \mathrm{~Hz}, \mathrm{NH})$, $5.89(\mathrm{t}, 0.55 \mathrm{H}, J 5.5 \mathrm{~Hz}, \mathrm{NH}), 5.35\left(\mathrm{dd}, 1 \mathrm{H}, J_{3^{\prime}, 4^{\prime}} 3.4 \mathrm{~Hz}, J_{4^{\prime}, 5^{\prime}} 0.3 \mathrm{~Hz}, \mathrm{H}-4^{\prime}\right), 5.18$ (dd, $1 \mathrm{H}$, $\left.J_{2,3}=J_{3.4}=9.4 \mathrm{~Hz}, \mathrm{H}-3\right), 5.13-5.10\left(\mathrm{~m}, 1 \mathrm{H}, J_{1^{\prime}, 2^{\prime}} 7.9 \mathrm{~Hz}, J_{2^{\prime}, 3^{\prime}} 10.4 \mathrm{~Hz}, \mathrm{H}-2^{\prime}\right), 4.98$ (dd, $\left.1 \mathrm{H}, \mathrm{H}-3^{\prime}\right)$, 4.88-4.83 (m, 1 H, H-2), 4.63 (d, 0.55 H, H-1), 4.60-4.56 (m, 1 H, H-6a), 4.55 (d, 0.45 H, H-1), 4.50 (d, 1 H, H-1'), 4.16-4.02 (m, 5 H, H-6b, H-6'a, H-6'b, H-4e $\mathrm{e}_{\mathrm{pyr}}, \mathrm{H}-6 \mathrm{e}_{\mathrm{pyr}}$ ), 3.90-3.86 (m, $1 \mathrm{H}$, H-5'), 3.79-3.70 (m, 2 H, H-4, OCH), 3.66-3.41 (m, 7 H, H-5, H-4a $\mathrm{a}_{\text {pyr }}, \mathrm{H}-5_{\mathrm{pyr}}, \mathrm{H}-6 \mathrm{a}_{\mathrm{pyr}}, \mathrm{NCH}, \mathrm{OCH}_{2}$ ), $3.22\left(\mathrm{~s}, 3 \mathrm{H}, \mathrm{NCH}_{3}\right), 3.21-3.12(\mathrm{~m}, 1 \mathrm{H}, \mathrm{NCH}), 2.17-2.04$ (ms, $18 \mathrm{H}, 6$ x OAc), 1.96 (s, $6 \mathrm{H}, \mathrm{NAc}$, OAc), 1.50 ( $2 \mathrm{~s}, 3 \mathrm{H}, \mathrm{CH}_{3}$ ); ESI HRMS: $m / z$ : calcd for $\mathrm{C}_{39} \mathrm{H}_{58} \mathrm{~N}_{2} \mathrm{O}_{23} \mathrm{Na}$ : 945.3323 , found: 945.3315 [M $+\mathrm{Na}]^{+}$.

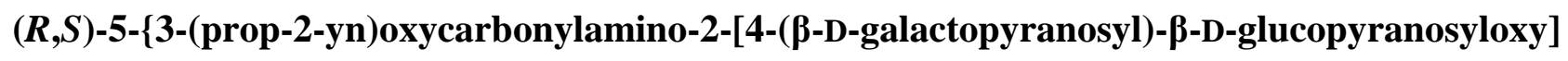
propoxy\}-2-methyl-1,3-dioxane-2-carboxylic acid (12). Acetate 10 (186 mg, $0.2 \mathrm{mmol}$ ) was dissolved in methanol $(4 \mathrm{~mL})$ and transferred to a plastic Falcon tube, then $4 \mathrm{M} \mathrm{NaOH}(0.5 \mathrm{~mL}$, $2 \mathrm{mmol}$ ) was added. The mixture was stirred at $80{ }^{\circ} \mathrm{C}$. After 3 days the reaction was not complete as checked by NMR. More $4 \mathrm{M} \mathrm{NaOH}(0.1 \mathrm{~mL}, 0.4 \mathrm{mmol})$ was added and stirring was continued overnight at $85{ }^{\circ} \mathrm{C}$. The mixture containing hydrolysis product 11 was treated with dry ice until the solution reached $\mathrm{pH} 8-9$. Then propargyl chloroformate $(40 \mu \mathrm{L}, 0.4 \mathrm{mmol})$ was added and the mixture was stirred at room temperature. After $2 \mathrm{~h}$ the mixture was purified on HPLC (C-18) using water containing $0.1 \%$ TFA-acetonitrile gradient. Two fractions were isolated, concentrated and freeze-dried. First fraction was the product of incomplete hydrolysis of $\mathbf{1 0}(R, S)-5$ - $\{3$-acetamido-2[4-( $\beta$-D-galactopyranosyl)- $\beta$-D-glucopyranosyloxy]propoxy $\}$-2-methyl-1,3-dioxane-2-carboxylic acid (11a) $(54 \mathrm{mg}, 45 \%),{ }^{1} \mathrm{H}-\mathrm{NMR}\left(\mathrm{D}_{2} \mathrm{O}\right) \delta: 4.56\left(\mathrm{~d}, 1 \mathrm{H}, J_{1,2} 7.9 \mathrm{~Hz}, \mathrm{H}-1\right), 4.44\left(\mathrm{~d}, 1 \mathrm{H}, J_{1^{\prime}, 2} 7.8 \mathrm{~Hz}\right.$, H-1'), 4.16 (dd, $\left.J_{\text {vic }} 4.5 \mathrm{~Hz}, J_{\text {gem }} 11.4 \mathrm{~Hz}, \mathrm{H}-4 \mathrm{e}_{\mathrm{pyr}}, \mathrm{H}-6 \mathrm{e}_{\mathrm{pyr}}\right), 4.02-3.99$ (m, $\left.1 \mathrm{H}, \mathrm{CH}\right), 3.95$ (dd, $1 \mathrm{H}, J_{5,6 \mathrm{a}}$ 
$\left.1.7 \mathrm{~Hz}, J_{6 \mathrm{a}, 6 \mathrm{~b}} 12.1 \mathrm{~Hz}, \mathrm{H}-6 \mathrm{a}\right), 3.06$ (d, 1 H, J' J', $3.3 \mathrm{~Hz}, \mathrm{H}-4^{\prime}$ ), 3.82 (m, 14 H, H-3, H-4, H-5, H-6b, H-2', H-3', H-5', H-6'a, H-6'b, H-4a $a_{\text {pyr }}$, H-5 pyr, H-6a $a_{\text {pyr }}, \mathrm{OCH}_{2}$ ), 3.40-3.29 (m, 3 H, H-2, NCH ) 2.00 (s, 3 H, OAc), 1.00 (s, $3 \mathrm{H}, \mathrm{CH}_{3}$ ); ESI HRMS: $\mathrm{m} / z$ : calcd for $\mathrm{C}_{23} \mathrm{H}_{39} \mathrm{NO}_{17}$ : 624.211; found: 624.2104 [M + $\mathrm{Na}]^{+}$. This intermediate can be recycled.

The second fraction was the target compound $12(59 \mathrm{mg}, 46 \%) ;{ }^{1} \mathrm{H}-\mathrm{NMR}\left(\mathrm{D}_{2} \mathrm{O}\right) \delta: 4.65$ (bs, $2 \mathrm{H}$, $\mathrm{CH}_{2}$ propargyl $), 4.56-4.50\left(\mathrm{~m}, 1 \mathrm{H}, J_{1.2} 7.9 \mathrm{~Hz}, \mathrm{H}-1\right), 4.42\left(\mathrm{~d}, 1 \mathrm{H}, J_{1^{\prime}, 2^{\prime}} 7.8 \mathrm{~Hz}, \mathrm{H}-1^{\prime}\right), 4.24-4.16$ $\left(\mathrm{m}, 2 \mathrm{H}, \mathrm{H}-4 \mathrm{e}_{\mathrm{pyr}}, \mathrm{H}-6 \mathrm{e}_{\mathrm{pyr}}\right), 4.00-3.88$ (m, $\left.3 \mathrm{H}, J_{3^{\prime}, 4^{\prime}} 3.3 \mathrm{~Hz}, \mathrm{H}-6 \mathrm{a}, \mathrm{H}-44^{\prime}, \mathrm{CH}\right), 3.86-3.50$ (m, 14 H, J',3 9.9 Hz, H-3, H-4, H-5, H-6b, H-2', H-3', H-5', H-6'a, H-6'b, H-4a H-6a $a_{\text {pyr }}, \mathrm{OCH}_{2}$ ), 3.30-3.24 (m, $3 \mathrm{H}, \mathrm{H}-2, \mathrm{NCH}_{2}$ ), 2.90 (bs, $1 \mathrm{H}, \mathrm{CH}_{\text {propargyl }}$ ), 1.52 (s, $3 \mathrm{H}, \mathrm{CH}_{3}$ ); ESI HRMS: $m / z$ : calcd for $\mathrm{C}_{25} \mathrm{H}_{38} \mathrm{NO}_{18}$ : 640.2094; found: $640.2091[\mathrm{M}-\mathrm{H}]^{-}$.

$(R, S)-5-\{3-(p r o p-2-y n) o x y c a r b o n y l a m i n o-2-[\alpha-D-g a l a c t o p y r a n o s y l-(1-4)-\beta$-D-galactopyranosyl(1-4)-ק-D-glucopyranosyloxy]propoxy\}-2-methyl-1,3-dioxane-2-carboxylic acid (13). Lactose derivative 12 (110 mg, $0.17 \mathrm{mmol}$ ) was dissolved in water $(1.5 \mathrm{~mL})$ and neutralized with dry $\mathrm{NaHCO}_{3}$. Then other components were added in the following order: 1 M HEPES buffer ( $\mathrm{pH}$ : 8; $0.93 \mathrm{~mL})$, DTT solution $(0.4 \mathrm{M}, 145 \mu \mathrm{L})$, alkaline phosphatase (1 U/ $\mu \mathrm{L}, 14.5 \mu \mathrm{L}$, Sigma), UDP-glucose (157 mg, $0.257 \mathrm{mmol}$ ) and crude fusion enzyme GalT/UDP-4'-epimerase [21] $(0.3 \mathrm{~mL})$. The mixture was incubated for $40 \mathrm{~h}$ at $37{ }^{\circ} \mathrm{C}$. The mixture was treated with Dowex $\mathrm{H}^{+}$resin, filtered and purified on HPLC (C-18) using water with $0.1 \%$ TFA and acetonitrile gradient. The fraction containing product was concentrated and lyophilized to afford the product $\mathbf{1 3}$ as a white foam $(116 \mathrm{mg}, 85 \%)$; ${ }^{1} \mathrm{H}-\mathrm{NMR}$ $\left(\mathrm{D}_{2} \mathrm{O}\right) \delta: 4.92\left(\mathrm{~d}, 1 \mathrm{H}, J_{1 " 2 "} 4.0 \mathrm{~Hz}, \mathrm{H}-1 "\right), 4.66\left(\mathrm{~d}, 2 \mathrm{H}, J 1.8 \mathrm{~Hz}, \mathrm{CH}_{2}\right.$ propargyl), 4.56-4.52 ( m, $1 \mathrm{H}$, $\left.J_{1,2} 7.6 \mathrm{~Hz}, \mathrm{H}-1\right), 4.50$ (d, $\left.1 \mathrm{H}, J_{1^{\prime}, 2^{\prime}} 7.8 \mathrm{~Hz}, \mathrm{H}-1^{\prime}\right), 4.34-4.31$ (m, $\left.1 \mathrm{H}, J_{5^{\prime \prime}, 6^{\prime \prime} \mathrm{a}}=J_{5^{\prime \prime}, 6^{\prime \prime}}=6.4 \mathrm{~Hz}, \mathrm{H}-5^{\prime \prime}\right)$,

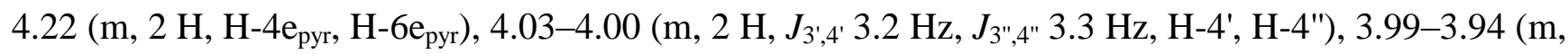
2 H, H-5, CH), 3.93-3.54 (m, 18 H, H-3, H-4, H-6a, H-6b, H-2', H-3', H-5', H-6'a, H-6'b, H-2",H-3", H-6"a, H-6"b, H-4a $a_{\text {pyr }}$, H-5 pyr, H-6a $a_{\text {pyr }}$, OCH $_{2}$ ), 3.38-3.27 (m, 3 H, H-2, NCH2), 2.89 (bs, $1 \mathrm{H}, \mathrm{CH}_{\text {propargyl }}$ ), 1.52 (s, $3 \mathrm{H}, \mathrm{CH}_{3}$ ); ESI HRMS: $m / z$ : calcd for $\mathrm{C}_{31} \mathrm{H}_{49} \mathrm{NO}_{23} \mathrm{Na}$ : 826.2588; found: $826.2588[\mathrm{M}+\mathrm{Na}]^{+}$.

4-Nitrophenyl 2-(2-(2-(prop-2-ynyloxy)ethoxy)ethoxy)ethyl carbonate (15). To a solution of 2-(2-(2-(prop-2-ynyloxy)ethoxy)ethoxy)ethanol 14 [15] (1.953 g, $10.37 \mathrm{mmol})$ and 4-nitrophenyl chloroformate $(2.51 \mathrm{~g}, 12.5 \mathrm{mmol})$ in dry DCM pyridine $(2 \mathrm{~mL})$ was slowly added at room temperature. After $30 \mathrm{~min}$ the reaction was quenched by addition of methanol, diluted with DCM and washed with brine. The organic layer was collected, concentrated and the residue was chromatographed on silica gel using hexane acetone (3:1) to provide $\mathbf{1 5}$ as a clear syrup (3.345 g; 91\%); ${ }^{1} \mathrm{H}-\mathrm{NMR}\left(\mathrm{CDCl}_{3}\right) \delta: 8.30-8.26$ and 7.42-7.37 (2 m, $\left.4 \mathrm{H}, \mathrm{C}_{6} \mathrm{H}_{4}\right), 4.46-4.42$ (m, $2 \mathrm{H}, \mathrm{CH}_{2} \mathrm{OCO}$ ), 4.20 (d, $2 \mathrm{H}, J 3.4 \mathrm{~Hz}, \mathrm{CH}_{2}$ propargyl), 3.84-3.80 (m, 2H, $\left.\mathrm{OCH}_{2}\right), 3.73-3.67$ (m, $\left.8 \mathrm{H}, 4 \times \mathrm{CH}_{2}\right), 2.43$ (t, 1 $\mathrm{H}, \mathrm{CH}_{\text {propargyl }}$; ESI HRMS: $m / z$ : calcd for $\mathrm{C}_{16} \mathrm{H}_{19} \mathrm{NO}_{8}$ : 376.1003 ; found: $376.1004[\mathrm{M}+\mathrm{Na}]^{+}$.

\section{$(R, S)-5-\{2-[\beta$-D-galactopyranosyl-(1-4)- $\beta$-D-glucopyranosyloxy]-5-oxo-6,9,12,15-tetraoxa-4-} azaoctadec-17-ynyloxy\}-2-methyl-1,3-dioxane-2-carboxylic acid (16). To a solution of 10 (545 mg, $0.59 \mathrm{mmol})$ in methanol $(12 \mathrm{~mL})$ in a plastic tube $\mathrm{NaOH}(4 \mathrm{M}, 2.25 \mathrm{~mL}, 9 \mathrm{mmol})$ was added and the mixture was stirred at $80{ }^{\circ} \mathrm{C}$ for 3 days. The mixture was diluted with water and treated with dry ice until the solution $\mathrm{pH}$ was $\sim 11$ at which point a solution of 4-nitrophenylcarbonate 15 (0.6 g, $1.7 \mathrm{mmol})$ in methanol $(2 \mathrm{~mL})$ was added. The mixture was stirred overnight at room temperature. The reaction was not complete. $\mathrm{Et}_{3} \mathrm{~N}(410 \mu \mathrm{L}, 3 \mathrm{mmol})$ and more $15(0.3 \mathrm{~g}, 0.85 \mathrm{mmol})$ were added and the mixture 
was stirred overnight. The reaction was not complete. The mixture was concentrated and purified by HPLC (C-18) using water with $0.1 \%$ of TFA and acetonitrile gradient to provide compound 16 (285 mg; 62\%) as a white foam; ${ }^{1} \mathrm{H}-\mathrm{NMR}\left(\mathrm{D}_{2} \mathrm{O}\right) \delta: 4.55-4.54\left(\mathrm{~m}, 1 \mathrm{H}, J_{1,2} 7.9 \mathrm{~Hz}, \mathrm{H}-1\right), 4.43(\mathrm{~d}, 1 \mathrm{H}$, $\left.J_{1^{\prime}, 2^{\prime}} 7.8 \mathrm{~Hz}, \mathrm{H}-1^{\prime}\right), 4.23$ (d, $2 \mathrm{H}, J 2.4 \mathrm{~Hz}, \mathrm{CH}_{2 \text { propargyl }}$ ), 4.22-4.15 (m, $4 \mathrm{H}, \mathrm{H}-4 \mathrm{e}_{\mathrm{pyr}}, \mathrm{H}-6 \mathrm{e}_{\mathrm{pyr}}, \mathrm{CH}_{2} \mathrm{OCO}$ ), 3.98-3.92 (m, 2 H, H-6a, CH), 3.91 (d, $\left.1 \mathrm{H}, J_{3^{\prime}, 4^{\prime}} 3.4 \mathrm{~Hz}, \mathrm{H}-4^{\prime}\right), 3.81-3.50$ (m, $24 \mathrm{H}$, $J_{2^{\prime}, 3^{\prime}} 9.9$ Hz, H-3, H-4, H-5, H-6b, H-2', H-3', H-5', H-6'a, H-6'b, H-4a $a_{\text {pyr }}$, H-5 pyr $_{1}$, H-6a $a_{\text {pyr }}, 6 \times$ OCH $_{2}$ ), 3.37-3.26 (m, $3 \mathrm{H}, \mathrm{H}-2$ ', $\mathrm{NCH}_{2}$ ), 2.89 (t, $1 \mathrm{H}, \mathrm{CH}$ propargyl), 1.50 (s, $3 \mathrm{H}, \mathrm{CH}_{3}$ ); ESI HRMS: $m / z$ : calcd for $\mathrm{C}_{31} \mathrm{H}_{51} \mathrm{NO}_{21} \mathrm{Na}$ : 796.2846; found: $796.2841[\mathrm{M}+\mathrm{Na}]^{+}$.

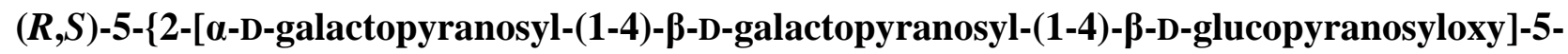
oxo-6,9,12,15-tetraoxa-4-azaoctadec-17-ynyloxy\}-2-methyl-1,3-dioxane-2-carboxylic acid (17). Lactose derivative 16 (273 $\mathrm{mg}, 0.35 \mathrm{mmol})$ was dissolved in water $(3 \mathrm{~mL})$ and neutralized with dry $\mathrm{NaHCO}_{3}$. Then other components were added in the following order: 1 M HEPES buffer (pH: 8; $1.86 \mathrm{~mL}$ ), DTT solution $(0.4 \mathrm{M}, 300 \mu \mathrm{L})$, alkaline phosphatase (1 U/ $\mu \mathrm{L}, 30 \mu \mathrm{L}$, Sigma), UDP-glucose (320 mg, $0.52 \mathrm{mmol}$ ) and crude fusion enzyme GalT/UDP-4'-epimerase [21] (0.5 mL). The mixture was incubated for $24 \mathrm{~h}$ at $37{ }^{\circ} \mathrm{C}$ then treated with Dowex $\mathrm{H}^{+}$resin, filtered and purified on HPLC (C-18) using water with $0.1 \%$ TFA and acetonitrile gradient. The fraction containing product was concentrated and lyophilized to afford the product 17 as a white foam $(272 \mathrm{mg} ; 82 \%) ;{ }^{1} \mathrm{H}-\mathrm{NMR}\left(\mathrm{D}_{2} \mathrm{O}\right)$ $\delta$ : 4.94 (m, $\left.1 \mathrm{H}, J_{1^{\prime \prime}, 2^{\prime \prime}} 4.0 \mathrm{~Hz}, \mathrm{H}-1^{\prime}\right), 4.67-4.65$ (m, $\left.1 \mathrm{H}, J_{1,2} 7.8 \mathrm{~Hz}, \mathrm{H}-1\right), 4.50$ (d, $1 \mathrm{H}, J_{1^{\prime}, 2^{\prime}} 7.7 \mathrm{~Hz}$, H-1'), 4.36-4.32 (m, $\left.1 \mathrm{H}, J_{5 ", 6 " \mathrm{a}}=J_{5 ", 6 " \mathrm{~b}}=6.4 \mathrm{~Hz}, \mathrm{H}-5 "\right), 4.24$ (d, $2 \mathrm{H}, J 2.4 \mathrm{~Hz}, \mathrm{CH}_{2}$ propargyl), 4.22-4.16 (m, 4 H, H-4e $\mathrm{e}_{\mathrm{pyr}}, \mathrm{H}-6 \mathrm{e}_{\mathrm{pyr}}, \mathrm{CH}_{2} \mathrm{OCO}$ ), 4.04-4.01 (m, 2 H, H-4', H-4"), 4.00-3.52 (m, 30 H, H-3, Н-4, Н-5, Н-6a, Н-6b, Н-2', H-3', Н-5', Н-6'a, Н-6'b, Н-2", Н-3", Н-6"a, Н-6"b, $\left.\mathrm{H}-4 \mathrm{a}_{\mathrm{pyr}}, \mathrm{H}-5_{\mathrm{pyr}}, \mathrm{H}-6 \mathrm{a}_{\mathrm{pyr}}, \mathrm{OCH}, 6 \times \mathrm{OCH}_{2}\right), 3.38-3.27$ (m, $\left.3 \mathrm{H}, \mathrm{H}-2, \mathrm{NCH}_{2}\right), 2.58$ (t, $1 \mathrm{H}, \mathrm{CH}_{\text {propargyl }}$ ), 1.50 (s, $\mathrm{CH}_{3}$ ); ESI HRMS: $m / z$ : calcd for $\mathrm{C}_{37} \mathrm{H}_{61} \mathrm{NO}_{26} \mathrm{Na}$ : 958.3374 ; found $958.3366[\mathrm{M}+\mathrm{Na}]^{+}$.

$N$-[3-(tert-Butyloxycarbonylamino)propyl]methacrylamide (19). To a solution of 1,3-diaminopropane $(1 \mathrm{~mL})$ in DCM (4 mL) methacrylic acid NHS ester $(0.36 \mathrm{~g}, 1.96 \mathrm{mmol})$ was added. The mixture was stirred at room temperature for $15 \mathrm{~min}$. The mixture was concentrated and the residue dissolved in methanol. To the solution di(tert-butoxy)carbonyl oxide $(2.5 \mathrm{~g}, 10 \mathrm{mmol})$ was added followed by triethylamine $(3 \mathrm{~mL}, 25 \mathrm{mmol})$. After $1 \mathrm{~h}$ the mixture was concentrated and the residue was chromatographed on silica gel using hexane-ethyl acetate (3:2) to give the title product 19 $(0.2 \mathrm{~g}, 42 \%) ;{ }^{1} \mathrm{H}-\mathrm{NMR}\left(\mathrm{CDCl}_{3}\right)$ $\delta: 6.74$ (broad s, $\left.1 \mathrm{H}, \mathrm{NH}\right), 5.73\left(\mathrm{~s}, 1 \mathrm{H}, \mathrm{CH}_{2}\right), 5.31\left(\mathrm{~s}, 1 \mathrm{H}, \mathrm{CH}_{2}\right), 4.96$ (broad s, $1 \mathrm{H}, \mathrm{NH}), 3.35$ (dd, $\left.2 \mathrm{H}, J 6.2 \mathrm{~Hz}, \mathrm{NCH}_{2}\right), 3.18\left(\mathrm{dd}, 2 \mathrm{H}, J 5.9 \mathrm{~Hz}, \mathrm{NCH}_{2}\right), 1.96(\mathrm{~s}, 3 \mathrm{H}$, $\left.\mathrm{CH}_{3}\right), 1.67-1.58\left(\mathrm{~m}, 2 \mathrm{H}, \mathrm{CH}_{2}\right), 1.43(\mathrm{~s}, 9 \mathrm{H}, t \mathrm{Bu})$. ESI HRMS: $m / z$ : calcd for $\mathrm{C}_{12} \mathrm{H}_{22} \mathrm{~N}_{2} \mathrm{O}_{3} \mathrm{Na}$ $\left([\mathrm{M}+\mathrm{Na}]^{+}\right): 265.15226$; found: 265.15212 .

tert-Butyl 2-(2-((4-nitrophenoxy)carbonyloxy)ethoxy)ethylcarbamate (21). 2-(2-Aminoethoxy)ethanol (2.17 g; $20.6 \mathrm{mmol})$ was dissolved in methanol $(10 \mathrm{~mL})$ and di(tert-butoxy)carbonyl oxide (6.75 g; $30.9 \mathrm{mmol}$ ) was added followed by triethylamine $(3.13 \mathrm{~g}, 30.9 \mathrm{mmol})$. After $30 \mathrm{~min}$ the mixture was concentrated and dried overnight under a vacuum provided by an oil pump. The residue was dissolved in dry DCM $(20 \mathrm{~mL})$ and p-nitrophenyl chloroformate $(5.18 \mathrm{~g}, 25.7 \mathrm{mmol})$ was added followed by pyridine $(3.26 \mathrm{~g}, 41.2 \mathrm{mmol})$. After $30 \mathrm{~min}$ the reaction was quenched by addition of methanol, then the mixture was diluted with DCM, washed with brine, concentrated and the residue was chromatographed on silica gel using hexane-acetone $(4: 1)$ to provide the product as slightly yellow syrup (7.146 g, 94\%); ${ }^{1} \mathrm{H}-\mathrm{NMR}\left(\mathrm{CDCl}_{3}\right) \delta$ : 8.24 and $7.40\left(2 \mathrm{~d}, 4 \mathrm{H}, \mathrm{C}_{6} \mathrm{H}_{4}\right), 4.90$ (broad s, $1 \mathrm{H}$, 
$\mathrm{NH}), 4.43$ (ddd, $2 \mathrm{H}, J 4.6 \mathrm{~Hz}, J 2.9 \mathrm{~Hz}, \mathrm{OCH}_{2}$ ), 3.77 (ddd, $2 \mathrm{H}, \mathrm{OCH}_{2}$ ), 3.58 (t, $2 \mathrm{H}, J 5.2 \mathrm{~Hz}, \mathrm{NCH}_{2}$ ), 3.38-3.00 (m, $\left.2 \mathrm{H}, \mathrm{NCH}_{2}\right), 1.45\left(\mathrm{~s}, 9 \mathrm{H}, t\right.$-Bu). ESI HRMS: $m / z$ : calcd for $\mathrm{C}_{16} \mathrm{H}_{22} \mathrm{~N}_{2} \mathrm{O}_{8} \mathrm{Na}\left([\mathrm{M}+\mathrm{Na}]^{+}\right)$: 393.12684; found 393.12652.

Copolymer of $N$-(2-hydroxypropyl)methacrylamide with methacrylamide 19 (20). A solution of $\mathrm{N}$-(2-hydroxypropyl)methacrylamide $(502.5 \mathrm{mg}, 3.5 \mathrm{mmol})$ and 19 (42 $\mathrm{mg}, 0.174 \mathrm{mmol})$ in degassed water $(7 \mathrm{~mL})$ was ultrasonicated under vacuum. A solution of ammonium persulfate $(7 \mathrm{mg}$ in $70 \mu \mathrm{L}$ of water) was added to the mixture followed by an aq. solution of cysteamine hydrochloride $(98 \mu \mathrm{L} ; 1 \mathrm{mg} / 100 \mu \mathrm{L})$. The reaction mixture was vortexed and incubated at $50{ }^{\circ} \mathrm{C}$ overnight then concentrated and dissolved in treated with TFA $(8 \mathrm{~mL})$. After $2 \mathrm{~h}$ the mixture was concentrated, the residue was dissolved in water, dialyzed extensively against deionized water, then freeze-dried to provide a white powder of aminated HPMA polymer $20(445 \mathrm{mg}, 82 \%) ;{ }^{1} \mathrm{H}-\mathrm{NMR}\left(\mathrm{D}_{2} \mathrm{O}\right) \delta: 4.00-3.90$ (broad s, $1 \mathrm{H}, \mathrm{CHOH}$ ), 3.30-3.00 (m, 2.2 H, $\mathrm{CH}_{2} \mathrm{~N}, \mathrm{CH}_{2} \mathrm{NH}_{2}$ ), 2.00-1.60 (m, $2 \mathrm{H}, \mathrm{CH}_{2}$ ), 1.60-0.80 (m, $6.3 \mathrm{H}, \mathrm{CH}_{2}, \mathrm{CH}_{3}$ ). Integration of ${ }^{1} \mathrm{H}-\mathrm{NMR}$ signals indicated $\sim 5 \%$ incorporation of propylenediamine.

\subsection{Elongation of Side Chains. Preparation of $\mathbf{2 2}$ and $\mathbf{2 3}$}

To a solution of the polymer $\mathbf{2 0}(70 \mathrm{mg})$ in dry DMF $(1 \mathrm{~mL})$ the linker 21 (46 mg, $0.123 \mathrm{mmol})$ was added followed by triethylamine $(25 \mathrm{mg}, 0.25 \mathrm{mmol})$. The mixture was stirred overnight then diluted with water, dialyzed against deionized water and freeze-dried. The dry product was dissolved in TFA $(2 \mathrm{~mL})$ and stirred at room temperature for $30 \mathrm{~min}$. The mixture was diluted with water $(8 \mathrm{~mL})$ carefully neutralized with dry sodium carbonate $(1.33 \mathrm{~g})$ in small portions. Then the solution was dialyzed against deionized water and lyophilized to give polymer 22 as white powder (62 $\mathrm{mg}$ ); ${ }^{1} \mathrm{H}-\mathrm{NMR}\left(\mathrm{D}_{2} \mathrm{O}\right) \delta: 4.5$ (bs, $8.3 \mathrm{H}, \mathrm{CH}_{2} \mathrm{OCO}$ ), 3.90 (bs, $100 \mathrm{H}, \mathrm{CHOH}_{\mathrm{HPMA}}$ ), 3.80 (bs, $21.8 \mathrm{H}, \mathrm{OCH}_{2}$ ), 3.30-2.95 (m, $\left.230 \mathrm{H}, \mathrm{NCH}_{2}\right), 2.20-0.60\left(\mathrm{~m}, 840 \mathrm{H}, \mathrm{CH}_{2}, \mathrm{CH}_{3}\right)$.

Polymer 22 ( $87 \mathrm{mg}, 0.029 \mathrm{mmol}$ ) was treated with linker 21 again as described for the synthesis of 22 to yield polymer 23 as white foam (78 mg); ${ }^{1} \mathrm{H}-\mathrm{NMR}\left(\mathrm{D}_{2} \mathrm{O}\right) \delta: 4.60-4.40\left(\mathrm{~m}, 18.5 \mathrm{H}, \mathrm{CH}_{2} \mathrm{OCO}\right)$, 3.90 (broad s, $100 \mathrm{H}, \mathrm{CHOH}), 3.35-3.20\left(\mathrm{~m}, 32 \mathrm{H}, \mathrm{OCH}_{2}\right), 3.65$ (broad s, $\left.11 \mathrm{H}, \mathrm{OCH}_{2}\right), 3.40-3.00$ (m, $\left.240 \mathrm{H}, \mathrm{NCH}_{2}\right), 2.10-0.60\left(\mathrm{~m}, 844 \mathrm{H}, \mathrm{CH}_{2}, \mathrm{CH}_{3}\right)$.

\subsection{Conjugation of Lactose Derivative. Preparation of Polymers $\mathbf{2 4 , 2 5}$, and $\mathbf{2 6}$}

To a clear solution of polymer $20(52.5 \mathrm{mg}, 0.018 \mathrm{mmol})$ and activated carbonate 2 [11] (3.7 $\mathrm{mg}$, $0.046 \mathrm{mmol})$ in dry DMF $(1 \mathrm{~mL})$ triethylamine $(9.5 \mathrm{mg}, 0.093 \mathrm{mmol})$ was added and the mixture was stirred at room temperature overnight. The reaction mixture was diluted with water and dialyzed against deionized water, then freeze-dried to afford the protected intermediate as white powder $(67.5 \mathrm{mg})$. The intermediate was dissolved in dry methanol $(2.5 \mathrm{~mL})$ and $\mathrm{NaOMe}(0.5 \mathrm{M}, 0.23 \mathrm{~mL})$ was added to the solution. The mixture was stirred at room temperature for $3 \mathrm{~h}$ and concentrated. The residue was dissolved in water $(2 \mathrm{~mL})$ and stirred for $1 \mathrm{~h}$ then dialyzed against deionized water and lyophilized to provide the product 24 as a white powder $(50 \mathrm{mg}) ;{ }^{1} \mathrm{H}-\mathrm{NMR}\left(\mathrm{D}_{2} \mathrm{O}\right) \delta: 5.64(\mathrm{~d}, 1 \mathrm{H}$, $\left.J_{1,2} 4.8 \mathrm{~Hz}, \mathrm{H}-1\right), 4.46$ (d, $\left.1 \mathrm{H}, J_{1^{\prime}, 2^{\prime}} 7.7 \mathrm{~Hz}, \mathrm{H}-1^{\prime}\right), 4.43-4.36$ (m, $\left.2 \mathrm{H}, \mathrm{H}-3, \mathrm{H}-6 \mathrm{a}\right), 4.30-4.15$ (m, 2 H, H-2, H-6b), 4.08-4.00 (m, 1 H, H-5), 3.94-3.88 (m, 21 H, J $3^{\prime}, 4^{\prime} 2.9$ Hz, H-4', CㅂO), 3.85-3.68 (m, 4 H, H-4, H-5', H-6a', H-6b'), 3.64 (dd, 1 H, J'2,3' 9.9 Hz, H-3'), 3.56 (dd, 1 H, H-2'), 3.30-3.00 (m, $\left.41 \mathrm{H}, \mathrm{NCH}_{2}\right), 2.20-0.60\left(\mathrm{~m}, 160 \mathrm{H}, \mathrm{CH}_{2}, \mathrm{CH}_{3}\right)$. 
Polymer 22 was processed in a similar manner to give conjugate 25 as white powder; ${ }^{1} \mathrm{H}-\mathrm{NMR}$ $\left(\mathrm{D}_{2} \mathrm{O}\right) \delta: 5.64\left(\mathrm{~d}, 1 \mathrm{H}, J_{1,2} 4.7 \mathrm{~Hz}, \mathrm{H}-1\right), 4.44\left(\mathrm{~d}, 1 \mathrm{H}, J_{1^{\prime}, 2^{\prime}} 7.7 \mathrm{~Hz}, \mathrm{H}-2^{\prime}\right), 4.42-4.36(\mathrm{~m}, 2 \mathrm{H}, \mathrm{H}-3$, H-6a), 4.30-4.14 (m, 4 H, H-2, H-6a, OCH $2 \mathrm{OCO}$ ), 4.10-3.60 (m, 34 H, H-4, H-5, H-6a, H-6b, H-3', H-4', H-5', H-6a', H-6b', OCH, $\mathrm{OCH}_{2}$ ), 3.58 (dd, 1-H, $\left.J_{2^{\prime}, 3^{\prime}} 9.0 \mathrm{~Hz}, \mathrm{H}-2^{\prime}\right), 3.40-3.00$ (m, 46 H, NCH$)^{2}$, 2.10-0.60 (m, $\left.173 \mathrm{H}, \mathrm{CH}_{2}, \mathrm{CH}_{3}\right)$.

Polymer 23 was processed in a similar manner to give conjugate 26 as white powder; ${ }^{1} \mathrm{H}-\mathrm{NMR}$ $\left(\mathrm{D}_{2} \mathrm{O}\right) \delta: 5.66\left(\mathrm{~d}, 1 \mathrm{H}, J_{1,2} 4.3 \mathrm{~Hz}, \mathrm{H}-1\right), 4.46\left(\mathrm{~d}, 1 \mathrm{H}, J_{1^{\prime}, 2^{\prime}} 7.8 \mathrm{~Hz}, \mathrm{H}-1^{\prime}\right), 4.44-4.16$ (m, $2 \mathrm{H}, \mathrm{H}-3$, H-6a), 4.28-4.18 (m, 4H, H-2, H-6b, $\mathrm{CH}_{2} \mathrm{OCO}$ ), 4.06-4.00 (m,1 H, H-5), 4.38-3.62 (m, 31 H, H-4, H-3', H-4', H-5', H-6a', H-6b', OCH, OCH ${ }_{2}$ ), 3.56 (dd, 1 H, J'2', 9.8 Hz, H-2'), 3.40-3.00 (m, 40 H, $\left.\mathrm{NCH}_{2}\right), 2.10-0.80\left(\mathrm{~m}, 140 \mathrm{H}, \mathrm{CH}_{2}, \mathrm{CH}_{3}\right)$.

\subsection{Enzymatic Galactosylation of HPMA-Lactose Polymers. Preparation of Trisaccharide Conjugates} HPMA-n0, HPMA-n1, and HPMA-n2

Polymer $24(41.5 \mathrm{mg})$ was dissolved in water $(506 \mu \mathrm{L})$ then HEPES buffer $(43 \mu \mathrm{L})$ was added, followed by aq. DTT solution $(0.4 \mathrm{M}, 10.6 \mu \mathrm{L})$ and alkaline phosphatase $(1 \mathrm{U} / \mu \mathrm{L}, 1.06 \mu \mathrm{L})$. UDP-Glc (12.6 mg, $0.02 \mathrm{mmol}$ ) was added and followed by crude fusion enzyme GalT/UDP-4'-epimerase [21] (32 $\mu \mathrm{L}$ ) and the mixture was incubated at $37{ }^{\circ} \mathrm{C}$ overnight. Then it was treated with aq. $10 \%$ trichloroacetic acid $(620 \mu \mathrm{L})$ and centrifuged. The solution was diluted with water and dialyzed against deionized water. The dialyzed solution was filtered through Milipore membrane $(0.45 \mu \mathrm{m})$ and lyophilized to give the product as a white powder. ${ }^{1} \mathrm{H}-\mathrm{NMR}$ of the sample indicated the reaction was $70 \%$ complete. Enzymatic reaction was repeated to achieve complete conversion to give HPMA-n0 as a white powder $(32 \mathrm{mg}) ;{ }^{1} \mathrm{H}-\mathrm{NMR}\left(\mathrm{D}_{2} \mathrm{O}\right) \delta: 5.68$ (bs, $\left.1 \mathrm{H}, \mathrm{H}-1\right), 4.96\left(\mathrm{~d}, 1 \mathrm{H}, J_{1}\right.$ ", 2" $\left.3.5 \mathrm{~Hz}, \mathrm{H}-1 "\right), 4.52$ (d, 1H, J $\left.J_{1,2} 7.6 \mathrm{~Hz}, \mathrm{H}-1\right)$, 4.46-4.34 (m, 3 H, H-3, H-5"), 4.28-4.18 (m, 2 H, H-2), 4.08-4.01 (m, 3 H, H-5, H-4', H-4"), 3.98-3.76 (m, 30 H, H-6a, H-6b, H-5', H-6a',H-6b', H-2", H-3", H-6a", H-6b", C $\underline{\mathrm{HOH}}$ ), 3.76-3.68 (m, 2H, H-4, H-3'), 3.60 (dd, 1 H, $\left.J_{2^{\prime}, 3^{\prime}} 9.7 \mathrm{~Hz}, \mathrm{H}-2^{\prime}\right), 3.60-3.00$ (m, $50 \mathrm{H}, \mathrm{NCH}_{2}$ ), 2.1-0.6 (m, $\left.198 \mathrm{H}, \mathrm{CH}_{2}, \mathrm{CH}_{3}\right)$.

Polymer 25 was processed in a similar manner to give conjugate HPMA-n1 as white powder; ${ }^{1} \mathrm{H}-\mathrm{NMR}\left(\mathrm{D}_{2} \mathrm{O}\right)$ 8: 5.64 (bs, $\left.1 \mathrm{H}, \mathrm{H}-1\right), 4.96$ (d, $\left.1 \mathrm{H}, J_{1^{\prime \prime 2}, 2} 3.3 \mathrm{~Hz}, \mathrm{H}-1 "\right), 4.52$ (d, $1 \mathrm{H}, J_{1,2^{\prime}} 7.9 \mathrm{~Hz}$, H-1'), 4.44 (m, 3 H, H-3, H-6a, H-5"), 4.30-4.16 (m, 4 H, H-2, H-6b, $\mathrm{CH}_{2} \mathrm{OCO}$ ), 4.04 (bs, 3 H, H-5, H-4', H-4"), 4.00-3.62 (m, 32 H, H-4, H-3',H-5', H-6a', H-6b', H-2", H-3", H-6a",H-6b", CH,CH $), 3.60$ $\left(\mathrm{dd}, \quad 1-\mathrm{H}, \quad J_{2^{\prime}, 3^{\prime}} \quad 8.7 \mathrm{~Hz}, \quad \mathrm{H}-2^{\prime}\right), \quad 3.40-3.00 \quad\left(\mathrm{~m}, 43 \mathrm{H}, \quad \mathrm{NCH}_{2}\right), \quad 2.10-0.80 \quad(\mathrm{~m}, \quad 157 \mathrm{H}$, $\mathrm{CH}_{2}, \mathrm{CH}_{3}$ ).

Polymer 26 was processed in a similar manner to give conjugate HPMA-n2 as white powder; ${ }^{1} \mathrm{H}-\mathrm{NMR}\left(\mathrm{D}_{2} \mathrm{O}\right)$ 8: 5.66 (bs, 1H, H-1), 4.95 (d, $\left.1 \mathrm{H}, \mathrm{H}-1 "\right), 4.52$ (d, $1 \mathrm{H}, \mathrm{H}-1$ '), 4.22-4.36 (m, $3 \mathrm{H}$, H-3, H-6a, H-5"), 4.28-4.16 (m, 4 H, H-2, H-6b, $\mathrm{CH}_{2} \mathrm{OCO}$ ), 4.04 (bs, 3 H, H-5, H-4', H-4"), 3.98-3.56 (m, 38 H, H-4, H-2', H-3', H-5', H-6a', H-6b', H-2", H-3", H-6a", H-6b", CH, CH ${ }_{2}$ ), 3.40-3.00 (m, $\left.49 \mathrm{H}, \mathrm{NCH}_{2}\right), 2.10-0.80\left(\mathrm{~m}, 175 \mathrm{H}, \mathrm{CH}_{2}, \mathrm{CH}_{3}\right)$.

N-(2-(2-(2-azidoethoxy)ethoxy)ethyl)methacrylamide (27, AzMA). To a solution of 2-(2-(2azidoethoxy)ethoxy)ethanamine [16] (3.17 g, $18.2 \mathrm{mmol})$ in DCM (15 mL) and methacrylic anhydride (4.2 g, $1.5 \mathrm{eq}$ ) was added followed by $\mathrm{Et}_{3} \mathrm{~N}$ (2 g, 3 eq) and the mixture was stirred for $30 \mathrm{~min}$. Chromatography on the silica gel in hexane-ethyl acetate (up to $70 \%$ ) gave 27 (2.8 g, 63\%). ${ }^{1} \mathrm{H}-\mathrm{NMR}$ 
$\left(\mathrm{CDCl}_{3}\right) \delta: 6.26(\mathrm{~s}, 1 \mathrm{H}, \mathrm{NH}), 5.68-5.67\left(\mathrm{~m}, 1 \mathrm{H}, \mathrm{CH}_{2}=\right), 5.32-5.30\left(\mathrm{~m}, 1 \mathrm{H}, \mathrm{CH}_{2}=\right), 3.68-3.62(\mathrm{~m}$, $6 \mathrm{H}, \mathrm{CH}_{2}$ ), 3.59 (t, $2 \mathrm{H}, J 4.7 \mathrm{~Hz}, \mathrm{CH}_{2}$ ), 3.51 (dd, $2 \mathrm{H}, J 5.5 \mathrm{~Hz}, J 10.8 \mathrm{~Hz}, \mathrm{CH}_{2}$ ), 3.37 (t, $2 \mathrm{H} \mathrm{J} \mathrm{4.8} \mathrm{Hz,}$ $\left.\mathrm{CH}_{2}\right), 1.95\left(\mathrm{~m}, 3 \mathrm{H}, \mathrm{CH}_{3}\right) ;{ }^{13} \mathrm{C}-\mathrm{NMR}\left(\mathrm{CDCl}_{3}\right) \delta: 168.408(\underline{\mathrm{C}}=\mathrm{O}), 140.078\left(\underline{\mathrm{C}}=\mathrm{CH}_{2}\right), 119.374$ $\left(\mathrm{C}=\underline{\mathrm{CH}}_{2}\right), 70.543\left(\mathrm{CH}_{2} \mathrm{O}\right), 70.236\left(\mathrm{CH}_{2} \mathrm{O}\right), 70.057\left(\mathrm{CH}_{2} \mathrm{O}\right), 69.843\left(\mathrm{CH}_{2} \mathrm{O}\right), 50.621\left(\underline{\mathrm{C}}-\mathrm{N}_{3}\right), 39.333$ $\left(\underline{\mathrm{C}} \mathrm{H}_{2}-\mathrm{NH}\right), 18.625\left(\underline{\mathrm{CH}}_{3}\right)$. ESI HRMS: $\mathrm{m} / z$ : calcd for $\mathrm{C}_{10} \mathrm{H}_{18} \mathrm{~N}_{4} \mathrm{O}_{3} \mathrm{Na}\left([\mathrm{M}+\mathrm{Na}]^{+}\right): 265.1271$; found 265.1271.

\subsection{Typical RAFT Polymerization of Hydroxypropyl Methacrylamide Monomer}

The statistical copolymerization AzMA and 2-hydroxylpropyl methacrylamide (HPMA) was performed at $70{ }^{\circ} \mathrm{C}$ in the presence of 4-cyanopentanoic acid dithiobenzoate (CTP) and 4,4'-azobis (4-cyanovaleric acid) (ACVA) as chain transfer agent and initiator, respectively. In a typical protocol, AzMA (0.18 mL, $0.4 \mathrm{mmol})$ and HPMA (1.1 g, $7.6 \mathrm{mmol})$ was dissolved in double distilled water containing a few drops of $\mathrm{HCl}(8 \mathrm{~mL})$ followed by the addition of CTP $(5 \mathrm{mg}, 18 \mu \mathrm{mol})$ and ACVA $(5 \mathrm{mg}, 18 \mu \mathrm{mol})$ in 2-propanol $(2 \mathrm{~mL})$ (targeted $\mathrm{DP}_{n}$ 422, Targeted molecular weight $61 \mathrm{kDa}$ ). The mixture was purged with nitrogen for 45 minutes and flask was placed in oil bath for polymerization under nitrogen for $24 \mathrm{~h}$. The polymerization was quenched using liquid nitrogen and polymer was precipitated in acetone. The molecular weight and molecular weight distributions of copolymers were determined using gel permeation chromatography in aqueous media.

\subsection{General Procedure for Preparation of Polymeric Narrow Molecular Weight Heterobifunctional Ligands}

An appropriate HPMA-AzMa copolymer $(20-25 \mathrm{mg})$ and monomeric heterobifunctional ligand $\left(5,13\right.$ or 17, 1.5-2.0 eq) were dissolved in water $(1 \mathrm{~mL})$ and neutralized with dry $\mathrm{NaHCO}_{3}$ (to $\left.\mathrm{pH}: 8\right)$, then $1 \mathrm{M}$ sodium ascorbate $(25 \mu \mathrm{L})$ and $0.05 \mathrm{M}(50 \mu \mathrm{L})$ were added and the solution was left on a tumbler for 2 days. The reaction was checked by IR for the presence of azide. When no azido group could be detected the reaction mixture was diluted with water and extensively dialyzed against deionized water with the addition of EDTA, then filtered and lyophilized. Product was obtained in the form of white powder.

HPMA-16/5-A; ${ }^{1} \mathrm{H}-\mathrm{NMR}\left(\mathrm{D}_{2} \mathrm{O}\right) \delta: 8.10\left(\mathrm{~s}, 1 \mathrm{H}, \mathrm{CH}_{\text {triazol }}\right), 7.80-7.50$ (m, $\left.24 \mathrm{H}, \mathrm{NH}_{\mathrm{HPMA}}\right), 5.62$ (d, 1 $\left.\mathrm{H}, J_{1,2} 4.8 \mathrm{~Hz}, \mathrm{H}-1\right), 5.20$ (bs, $2 \mathrm{H}, \mathrm{OCH}_{2}$ ), 4.94 (d, $1 \mathrm{H}, J_{1 " 2 "}$ " $\left.3.9 \mathrm{~Hz}, \mathrm{H}-1 "\right), 4.60-4.53$ (m, 2H, NCH$)_{2}$, $4.52\left(\mathrm{~d}, 1 \mathrm{H}, J_{1^{\prime}, 2^{\prime}} 7.7 \mathrm{~Hz}, \mathrm{H}-1^{\prime}\right), 4.42-4.35$ (m, $\left.3 \mathrm{H}, \mathrm{H}-3, \mathrm{H}-6 \mathrm{a}, \mathrm{H}-5 "\right)$, 4.25-4.20 (m, $1 \mathrm{H}$, H-6b), 4.19-4.16 (m, 1 H, H-2), 4.05-4.00 (m, 3 H, H-5, H-4', H-4"), 3.96-3.56 (m, 51 H, H-4, H-2', H-3', H-5', H-6'a, H-2", Н-3", Н-6"a, H-6"b, $4 \times \mathrm{OCH}_{2}, \mathrm{CHOH} \mathrm{нРмА),} \mathrm{3.40-3.00} \mathrm{(m,} 60$ H, $2 \times \mathrm{NCH}_{2}, \mathrm{NCH}_{2 \text { HPMA }}$, 2.00-0.60 (m, $228 \mathrm{H}, \mathrm{CH}_{3}, \mathrm{CH}_{2 \text { HPMA }}, \mathrm{CH}_{3 \text { HPMA }}$ ).

HPMA-44/5-A; ${ }^{1} \mathrm{H}-\mathrm{NMR}\left(\mathrm{D}_{2} \mathrm{O}\right) \delta: 8.1\left(\mathrm{~s}, 1 \mathrm{H}, \mathrm{CH}_{\text {triazol }}\right), 5.62\left(\mathrm{~d}, 1 \mathrm{H}, J_{1,2} 4.9 \mathrm{~Hz}, \mathrm{H}-1\right), 5.20$ (bs, 2 $\left.\mathrm{H}, \mathrm{OCH}_{2}\right), 4.94$ (d, $\left.1 \mathrm{H}, J_{1^{\prime \prime 2}, 2^{\prime \prime}} 3.9 \mathrm{~Hz}, \mathrm{H}-1^{\prime \prime}\right), 4.60-4.54\left(\mathrm{~m}, 2 \mathrm{H}, \mathrm{NCH}_{2}\right), 4.51$ (d, $\left.1 \mathrm{H}, J_{1^{\prime}, 2^{\prime}} 7.7 \mathrm{~Hz}, \mathrm{H}-1^{\prime}\right)$, 4.42 (m, 3 H, H-3, H-6a, H-5"), 4.22 (m, 1 H, H-6b), 4.17 (m, 1 H, H-2), 4.06-3.99 (m, 3 H, H-5, Н-4', Н-4"), 3.97-3.86 (m, 20 H, H-6'a, H-3",CHOH нрмА), 3.86-3.54 (m, 16 H, H-4, H-2', H-3', H-5', H-6'b, H-2", H-6"a, H-6"b, $4 \times \mathrm{OCH}_{2}$ ), 3.70-3.00 (m, $38 \mathrm{H}, 2 \times \mathrm{NCH}_{2}, \mathrm{NCH}_{2}$ HPMA), 2.00-0.60 (m, $\left.136 \mathrm{H}, \mathrm{CH}_{3}, \mathrm{CH}_{2}, \mathrm{CH}_{3 \text { HPMA }}\right)$. 
HPMA-35/10-A; ${ }^{1} \mathrm{H}-\mathrm{NMR}\left(\mathrm{D}_{2} \mathrm{O}\right) \delta: 8.06\left(\mathrm{~s}, 1 \mathrm{H}, \mathrm{CH}_{\text {triazol }}\right), 5.62\left(\mathrm{~d}, 1 \mathrm{H}, J_{1,2} 4.9 \mathrm{~Hz}, \mathrm{H}-1\right), 5.20$ (bs, $\left.2 \mathrm{H}, \mathrm{OCH}_{2}\right), 4.94\left(\mathrm{~d}, 1 \mathrm{H}, J_{1^{\prime \prime}, 2^{\prime \prime}} 4.0 \mathrm{~Hz}, \mathrm{H}-1^{\prime \prime}\right), 4.60-4.53\left(\mathrm{~m}, 2 \mathrm{H}, \mathrm{NCH}_{2}\right), 4.51\left(\mathrm{~d}, 1 \mathrm{H}, J_{1^{\prime}, 2^{\prime}}\right.$ 7.7 Hz, H-1'), 4.42-4.34 (m, 3 H, H-3, H-6a, H-5"), 4.22-4.20 (m, 1 H, H-6b), 4.19-4.16 (m, 1 H, H2), 4.04-4.00 (m, 3 H, H-5, H-4', H-4"), 3.96-3.86 (m, 13 H, H-6'a, H-3",CHOH нРмА), 3.86-3.54 (m, 16 H, H-4, H-2', H-3', H-5', H-6'b, H-2", H-6"a, H-6"b, $4 \times \mathrm{OCH}_{2}$ ), 3.90-2.90 (m, 28 H, $2 \times \mathrm{NCH}_{2}, \mathrm{NCH}_{2}$ HPMA), 2.00-0.60 (m, $100 \mathrm{H}, \mathrm{CH}_{3}, \mathrm{CH}_{2}, \mathrm{CH}_{3 \text { HPMA }}$ ).

HPMA-20/15-A; ${ }^{1} \mathrm{H}-\mathrm{NMR}\left(\mathrm{D}_{2} \mathrm{O}\right) \delta: 8.10\left(\mathrm{~s}, 1 \mathrm{H}, \mathrm{CH}_{\text {triazol }}\right), 5.62\left(\mathrm{~d}, 1 \mathrm{H}, J_{1,2} 4.6 \mathrm{~Hz}, \mathrm{H}-1\right), 5.20$ (bs, $\left.2 \mathrm{H}, \mathrm{OCH}_{2}\right), 4.95\left(\mathrm{~d}, 1 \mathrm{H}, J_{1^{\prime \prime}, 2^{\prime \prime}} 3.9 \mathrm{~Hz}, \mathrm{H}-1^{\prime \prime}\right), 4.60-4.53\left(\mathrm{~m}, 2 \mathrm{H}, \mathrm{NCH}_{2}\right), 4.52\left(\mathrm{~d}, 1 \mathrm{H}, J_{1^{\prime}, 2^{\prime}}\right.$ 7.7 Hz, H-1'), 4.42-4.36 (m, 3 H, H-3, H-6a, H-5"), 4.26-4.20 (m, 1 H, H-6b), 4.19-4.15 (m, 1 H, H-2), 4.05-4.01 (m, 3 H, H-5, H-4', H-4"), 3.96-3.86 (m, 12 H, H-6'a, H-3",CHOH нPмA), 3.86-3.54 (m, 16 H, H-4, H-2', H-3', H-5', H-6'b, H-2", H-6"a, H-6"b, $4 \times \mathrm{OCH}_{2}$ ), 3.90-3.00 (m, 26 H, $2 \times \mathrm{NCH}_{2}, \mathrm{NCH}_{2}$ HPMA $), 2.20-0.60$ (m, $90 \mathrm{H}, \mathrm{CH}_{3}, \mathrm{CH}_{2}$ HPMA, $\mathrm{CH}_{3}$ HPMA$)$.

HPMA-37/15-A; ${ }^{1} \mathrm{H}-\mathrm{NMR}\left(\mathrm{D}_{2} \mathrm{O}\right) \delta: 8.10\left(\mathrm{~s}, 1 \mathrm{H}, \mathrm{CH}_{\text {triazol }}\right), 5.62$ (d, $\left.1 \mathrm{H}, J_{1,2} 4.8 \mathrm{~Hz}, \mathrm{H}-1\right), 5.20$ (bs, $\left.2 \mathrm{H}, \mathrm{OCH}_{2}\right), 4.94\left(\mathrm{~d}, 1 \mathrm{H}, J_{1^{\prime \prime 2}, 2} 3.9 \mathrm{~Hz}, \mathrm{H}-1 "\right), 4.60-4.54\left(\mathrm{~m}, 2 \mathrm{H}, \mathrm{NCH}_{2}\right), 4.51(\mathrm{~d}, 1 \mathrm{H}$, $J_{1^{\prime}, 2^{\prime}} 7.7$ Hz, H-1'), 4.42-4.34 (m, 3 H, H-3, H-6a, H-5"), 4.24-4.19 (m, 1 H, H-6b), 4.19-4.16 (m, 1 H, H-2), 4.04-4.01 (m, 3 H, H-5, H-4', H-4"), 3.96-3.86 (m, 11 H, H-6'a, H-3",CHOH нPмA), 3.863.54 (m, 16 H, H-4, H-2', H-3', H-5', H-6'b, H-2", H-6"a, H-6"b, $4 \times \mathrm{OCH}_{2}$ ), 3.90-3.00 (m, $22 \mathrm{H}, 2 \times \mathrm{NCH}_{2}, \mathrm{NCH}_{2}$ HPMA $), 2.20-0.60\left(\mathrm{~m}, 80 \mathrm{H}, \mathrm{CH}_{3}, \mathrm{CH}_{2} \mathrm{HPMA}, \mathrm{CH}_{3} \mathrm{HPMA}\right)$.

HPMA-44/5-B; ${ }^{1} \mathrm{H}-\mathrm{NMR}\left(\mathrm{D}_{2} \mathrm{O}\right) \delta: 8.10$ (s, $\left.1 \mathrm{H}, \mathrm{CH}_{\text {triazol }}\right), 5.20$ (bs, $\left.2 \mathrm{H}, \mathrm{OCH}_{2}\right), 4.94\left(\mathrm{~d}, 1 \mathrm{H}, J_{1^{\prime \prime}, 2^{\prime \prime}}\right.$ $3.8 \mathrm{~Hz}, \mathrm{H}-1 "), 4.62-4.47$ (m, $4 \mathrm{H}, \mathrm{H}-1, \mathrm{H}-1$ ', $\mathrm{NCH}_{2}$ ), 4.34 (dd, $1 \mathrm{H}, J_{5^{\prime \prime}, 6 " \mathrm{a}} \sim J_{5^{\prime \prime}, 6 " \mathrm{~b}} \sim 6.5 \mathrm{~Hz}$, H-5"), 4.12-3.99 (m, 4 H, H-4', H-4", H-4e pyr , H-6e $\mathrm{e}_{\mathrm{pyr}}$ ), 3.99-3.46 (m, 40 H, H-3, H-4, H-6a, H-6b, H-

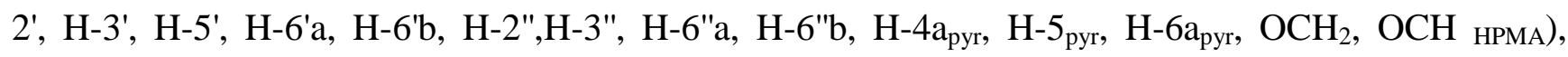
3.35-2.96 (m, 45 H, H-2, NCH 2 HPMA), 2.00-0.06 (m, 176 H, $\mathrm{CH}_{3}, \mathrm{CH}_{2}$ HPMA, $\mathrm{CH}_{3 \text { HPMA}}$ ).

HPMA-35/10-B; ${ }^{1} \mathrm{H}-\mathrm{NMR}\left(\mathrm{D}_{2} \mathrm{O}\right) \delta: 8.10\left(\mathrm{~s}, 1 \mathrm{H}, \mathrm{CH}_{\text {triazol }}\right), 5.20\left(\mathrm{bs}, 2 \mathrm{H}, \mathrm{OCH}_{2}\right), 4.94\left(\mathrm{~d}, 1 \mathrm{H}, J_{1^{\prime \prime}, 2^{\prime \prime}}\right.$ $3.8 \mathrm{~Hz}, \mathrm{H}-1 "), 4.63-4.47$ (m, $4 \mathrm{H}, \mathrm{H}-1, \mathrm{H}-1$ ', $\mathrm{NCH}_{2}$ ), 4.34 (dd, $1 \mathrm{H}, J_{5^{\prime \prime}, 6 " \mathrm{a}} \sim J_{5^{\prime \prime}, 6 " \mathrm{~b}} \sim 6.4 \mathrm{~Hz}$, H-5"), 4.12-4.00 (m, 4 H, H-4', H-4", H-4e $\mathrm{pyr}, \mathrm{H}-6 \mathrm{e}_{\mathrm{pyr}}$ ), 3.98-3.46 (m, 41 H, H-3, H-4, H-6a, H-6b,

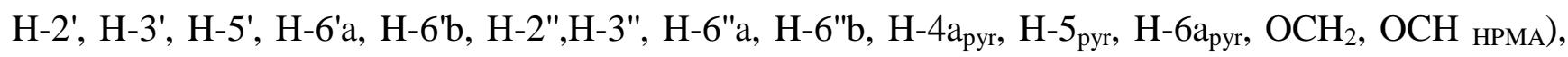
3.35-2.96 (m, $41 \mathrm{H}, \mathrm{H}-2, \mathrm{NCH}_{2}$ HPMA $), 2.00-0.06$ (m, $160 \mathrm{H}, \mathrm{CH}_{3}, \mathrm{CH}_{2 \text { HPMA }}, \mathrm{CH}_{3 \text { HPMA}}$ ).

HPMA-44/5-C; ${ }^{1} \mathrm{H}-\mathrm{NMR}\left(\mathrm{D}_{2} \mathrm{O}\right) \delta: 8.10\left(\mathrm{~s}, 1 \mathrm{H}, \mathrm{CH}_{\text {triazol }}\right), 7.90-7.40$ (m, $\left.18 \mathrm{H}, \mathrm{NH}_{\mathrm{HPMA}}\right), 4.94$ (d, 1

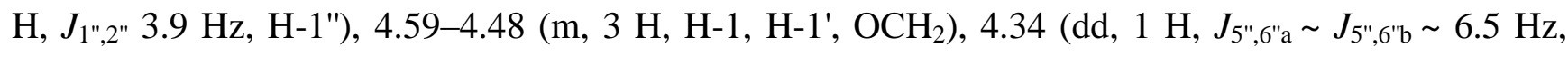
H-5"), 4.23-4.16 (m, 2 H, CH $\mathrm{CH}_{2} \mathrm{OCO}$ ), 4.14-4.06 (m, 2 H, H-4e $\mathrm{e}_{\mathrm{pyr}}, \mathrm{H}-6 \mathrm{e}_{\mathrm{pyr}}$ ), 4.04-4.00 (m, 2H, H-4', H-4"), 3.98-3.49 (m, 54 H, H-3, H-4, H-5, H-6a, H-6b, H-2', H-3', H-5', H-6'a, Н-6'b, H-2", H-3", H-6"a, H-6"b, H-4a a pyr H-5 pyr, H-6a $a_{\text {pyr }}, \mathrm{OCH}, 6 \times \mathrm{OCH}_{2}, \mathrm{OCH}_{\mathrm{HPMA}}$ ), 3.47-3.00 (m, 45 H, $\mathrm{H}-2, \mathrm{NCH}_{2}, \mathrm{NCH}_{2} \mathrm{HPMA}$ ), 2.10-0.60 (m, $176 \mathrm{H}, \mathrm{CH}_{3}, \mathrm{CH}_{2}$ HPMA, $\mathrm{CH}_{3 \text { HPMA}}$ ).

HPMA-35/10-C; ${ }^{1} \mathrm{H}-\mathrm{NMR}\left(\mathrm{D}_{2} \mathrm{O}\right) \delta: 8.10\left(\mathrm{~s}, 1 \mathrm{H}, \mathrm{CH}_{\text {triazol }}\right), 7.90-7.40$ (m, $\left.13 \mathrm{H}, \mathrm{NH}_{\mathrm{HPMA}}\right), 4.94$ (d, $\left.1 \mathrm{H}, J_{1 ", 2 "} 3.9 \mathrm{~Hz}, \mathrm{H}-1 "\right), 4.60-4.48$ (m, $3 \mathrm{H}, \mathrm{H}-1, \mathrm{H}-1$ ', $\mathrm{OCH}_{2}$ ), 4.34 (dd, $1 \mathrm{H}, J_{5^{\prime \prime}, 6^{\prime \prime}}=J_{5^{\prime \prime}, 6 " \mathrm{~b}}=6.5 \mathrm{~Hz}$, H-5"), 4.25-4.17 ( m, 2 H, CH $2 \mathrm{OCO}$ ), 4.14-4.06 (m, 2 H, H-4e $\mathrm{eyr}_{\text {pr }}, \mathrm{H}-6 \mathrm{e}_{\mathrm{pyr}}$ ), 4.04-4.00 (m, 2 H, H-4', H-4"), 4.00-3.48 (m, 46 H, H-3, H-4, H-5, H-6a, H-6b, H-2', H-3', H-5', H-6'a, Н-6'b, H-2", H-3", H-6"a, H-6"b, H-4a $a_{\text {pyr }}$, H-5 pyr, H-6a $a_{\text {pyr }}, 6 \times$ OCH $_{2}, \mathrm{OCH}_{\text {HPMA }}$ ), 3.48-3.00 (m, 37 H, H-2, $2 \times \mathrm{NCH}_{2}, \mathrm{NCH}_{2}$ HPMA $), 2.10-0.60$ (m, $136 \mathrm{H}, \mathrm{CH}_{3}, \mathrm{CH}_{2}$ HPMA, $\mathrm{CH}_{3}$ HPMA). 


\subsection{Typical RAFT Polymerization of Acrylamide Monomers}

The statistical copolymerization of 3-aminopropyl methacrylamide (APMA) and acrylamide (AA) was performed at $70{ }^{\circ} \mathrm{C}$ in the presence of 4-cyanopentanoic acid dithiobenzoate (CTP) and 4, 4'-azobis(4-cyanovaleric acid) (ACVA) as chain transfer agent and initiator, respectively. In a typical protocol AA (2 g, $28 \mathrm{mmol})$ and APMA $(0.25 \mathrm{~g}, 1.4 \mathrm{mmol})$ was dissolved in dimethylsulfoxide (DMSO) $(10 \mathrm{~mL})$ followed by the addition of CTP $(8 \mathrm{mg}, 29 \mu \mathrm{mol})$ and ACVA $(2 \mathrm{mg}, 7 \mu \mathrm{mol})$ (targeted $\mathrm{DP}_{n}$ 977, Targeted molecular weight $70 \mathrm{kDa}$ ). The mixture was purged with nitrogen for 45 minutes and flask was placed in oil bath for polymerization under nitrogen for $24 \mathrm{~h}$. The polymerization reaction mixture was quenched using liquid nitrogen and polymer was precipitated in acetone. The molecular weight and molecular weight distributions of copolymers were determined using aqueous gel permeation chromatography.

PAA-27/5. Poly[acrylamide-co-(3-aminopropylmethacrylamide hydrochloride)] (M.W.: 27000; 5\% of amine; $210 \mathrm{mg}, 141 \mu \mathrm{mol})$ was dissolved in water $(2.5 \mathrm{~mL})$ and imidazole-1-sulfonyl azide [17] (118 mg, $563 \mu \mathrm{mol}$ ) was added followed by $0.4 \mathrm{M}$ solution of $\mathrm{CuSO}_{4} / \mathrm{H}_{2} \mathrm{O}(12.5 \mu \mathrm{L})$ and $\mathrm{pH}$ of the solution was adjusted to 10 by addition of $5 \mathrm{M} \mathrm{NaOH}(200 \mu \mathrm{L})$. The reaction mixture was stirred at room temperature for $6 \mathrm{~h}$, then dialyzed, filtered and lyophilized to provide the product as an off white powder (177 mg). IR: $2103.0 \mathrm{~cm}^{-1},{ }^{1} \mathrm{H}-\mathrm{NMR}\left(\mathrm{D}_{2} \mathrm{O}\right) \delta: 3.44-3.35\left(\mathrm{~m}, 2 \mathrm{H}, \mathrm{NCH}_{2}\right), 3.32-3.12(\mathrm{~m}, 2 \mathrm{H}$, $\mathrm{NCH}_{2}$ ), 2.38-1.98 (m, $16 \mathrm{H}, \mathrm{CH}_{2}$ linker, $\left.\mathrm{CH}\right), 1.84-1.34$ (m, $\left.32 \mathrm{H}, \mathrm{CH}_{2}\right), 1.2-1.08$ (m, $\left.3 \mathrm{H}, \mathrm{CH}_{3}\right)$.

PAA-72/5. The title product was obtained from poly[acrylamide-co-(3-aminopropylmethacrylamide hydrochloride)] as described for preparation of PAA-27/5 (M.W.: 72000; 5\% of amine; $210 \mathrm{mg}$, $141 \mu \mathrm{mol})$ as described for PAA-27/5. The title product obtained as off white powder $(156 \mathrm{mg})$. IR: $2103.9 \mathrm{~cm}^{-1}$. ${ }^{1} \mathrm{H}-\mathrm{NMR}\left(\mathrm{D}_{2} \mathrm{O}\right) \delta: 3.44-3.34\left(\mathrm{~m}, 2 \mathrm{H}, \mathrm{NCH}_{2}\right), 3.30-3.12\left(\mathrm{~m}, 2 \mathrm{H}, \mathrm{NCH}_{2}\right), 2.38-1.98$ (m, $16 \mathrm{H}, \mathrm{CH}_{2}$ linker, $\left.\mathrm{CH}\right), 1.82-1.34\left(\mathrm{~m}, 34 \mathrm{H}, \mathrm{CH}_{2}\right), 1.2-1.08\left(\mathrm{~m}, 3 \mathrm{H}, \mathrm{CH}_{3}\right)$.

PAA-27/5-A. Azide PAA-27/5 $(21.8 \mathrm{mg}, 14.3 \mu \mathrm{mol})$ and 5 (23.5 mg, $28.3 \mu \mathrm{mol})$ were dissolved in water $(1 \mathrm{~mL})$ and $\mathrm{pH}$ adjusted to 8 . Then $1 \mathrm{M}$ sodium ascorbate $(25 \mu \mathrm{L})$ and $0.05 \mathrm{M}$ copper sulfate $(50 \mu \mathrm{L})$. The reaction mixture was left on a tumbler for 2 days. Then it was dialyzed, filtered and freeze-dried to afford the polymer PAA-27/5-A as a white powder $(35 \mathrm{mg}) .{ }^{1} \mathrm{H}-\mathrm{NMR}\left(\mathrm{D}_{2} \mathrm{O}\right) \delta: 8.06$ (s, $\left.1 \mathrm{H}, \mathrm{CH}_{\text {triazol }}\right), 5.62\left(\mathrm{~d}, 1 \mathrm{H}, J_{1,2} 4.9 \mathrm{~Hz}, \mathrm{H}-1\right), 5.18\left(\mathrm{bs}, 2 \mathrm{H}, \mathrm{OCH}_{2}\right), 4.94\left(\mathrm{~d}, 1 \mathrm{H}, J_{1^{\prime \prime}, 2^{\prime \prime}} 3.9 \mathrm{~Hz}\right.$, H-1"), 4.51 (d, 1 H, $J_{1^{\prime}, 2^{\prime}} 7.8$ Hz, H-1'), 4.50-4.35 (m, 5 H, J6a,6b 12.0 Hz, H-3, H-6a, H-5", NCH $), 4.23$ (dd, $\left.1 \mathrm{H}, J_{5,6 \mathrm{~b}} 5.1 \mathrm{~Hz}, \mathrm{H}-6 \mathrm{~b}\right), 4.18$ (dd, $\left.1 \mathrm{H}, J_{2,3} 3.9 \mathrm{~Hz}, \mathrm{H}-2\right), 4.04-4.01$ (m, $3 \mathrm{H}, \mathrm{H}-5, \mathrm{H}-4$ ', H-4"), 3.94-3.89 (m, 2 H, H-6'a, H-3"), 3.85-3.60 (m, 16 H, H-4, H-2', H-3', H-5', H-6'b, H-2", H-6"a, H-6"b, $4 \times \mathrm{OCH}_{2}$ ), 3.34-3.29 (m, 4 H, $2 \times \mathrm{NCH}_{2}$ ), 3.20-3.02 (m, $\left.2 \mathrm{H}, \mathrm{NCH}_{2}\right), 2.40-2.00$ (m, $16 \mathrm{H}, \mathrm{CH}_{2}, \mathrm{CH}_{\text {PAA }}$ ), 1.80-1.30 (m, $31 \mathrm{H}, \mathrm{CH}_{3}, \mathrm{CH}_{2 \text { PAA }}$ ), 1.20-1.00 (m, $3 \mathrm{H}, \mathrm{CH}_{3 \text { MAA }}$ ).

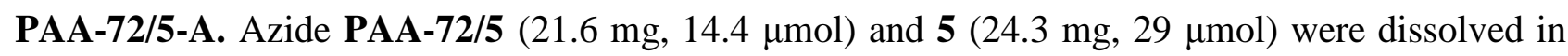
water $(1 \mathrm{~mL})$ and reaction and work-up were performed as described for PAA-27/5-A. The tile PAA-72/5-A was obtained as a white powder $(35.3 \mathrm{mg}) .{ }^{1} \mathrm{H}-\mathrm{NMR}\left(\mathrm{D}_{2} \mathrm{O}\right) \delta: 8.10\left(\mathrm{~s}, 1 \mathrm{H}, \mathrm{CH}_{\text {triazol }}\right)$, $5.62\left(\mathrm{~d}, 1 \mathrm{H}, J_{1,2} 4.9 \mathrm{~Hz}, \mathrm{H}-1\right), 5.18$ (bs, $2 \mathrm{H}, \mathrm{OCH}_{2}$ ), 4.94 (d, $\left.1 \mathrm{H}, J_{1 ", 2 "} 3.9 \mathrm{~Hz}, \mathrm{H}-1^{\prime \prime}\right), 4.51$ (d, $1 \mathrm{H}$, $\left.J_{1^{\prime}, 2^{\prime}} 7.7 \mathrm{~Hz}, \mathrm{H}-1^{\prime}\right), 4.49-4.34$ (m, 5 H, $J_{6 \mathrm{a}, 6 \mathrm{~b}} 11.8 \mathrm{~Hz}, \mathrm{H}-3, \mathrm{H}-6 \mathrm{a}, \mathrm{H}-5 ", \mathrm{NCH}_{2}$ ), 4.23 (dd, $1 \mathrm{H}$, $J_{5,6 \mathrm{~b}} 5.1 \mathrm{~Hz}, \mathrm{H}-6 \mathrm{~b}$ ), 4.18 (dd, 1 H, $J_{2,3} 4.0 \mathrm{~Hz}, \mathrm{H}-2$ ), 4.05-4.00 (m, 3 H, H-5, H-4', H-4"), 3.94-3.89 (m, 2 H, H-6'a, H-3"), 3.85-3.60 (m, 16 H, H-4, H-2', H-3', H-5', H-6'b, H-2", H-6"a, H-6"b, 
$\left.4 \times \mathrm{OCH}_{2}\right), 3.34-3.28\left(\mathrm{~m}, 4 \mathrm{H}, 2 \times \mathrm{NCH}_{2}\right), 3.20-3.02\left(\mathrm{~m}, 2 \mathrm{H}, \mathrm{NCH}_{2}\right), 2.40-1.90\left(\mathrm{~m}, 19 \mathrm{H}, \mathrm{CH}_{2}\right.$, $\mathrm{CH}_{\text {PAA }}$ ), 1.80-1.30 (m, $36 \mathrm{H}, \mathrm{CH}_{3}, \mathrm{CH}_{2}$ PAA $), 1.20-1.00$ (m, $3 \mathrm{H}, \mathrm{CH}_{3 \mathrm{MAA}}$ ).

\subsection{Biological Evaluation}

The solid-phase binding-inhibition and Vero cell cytotoxicity-neutralization assays are fully described in previous reports [11,18,19]. In brief, C57BL/6-Tg(APSC)1Imeg transgenic mice [20], which exhibit liver-specific expression of human SAP at a stable circulating serum concentration of 30-40 $\mu \mathrm{g} / \mathrm{mL}$, were used in the Stx1-mediated Shigatoxemia experiments. All experiments were conducted in a double-blind, placebo-controlled manner. All animal protocols were reviewed and approved (Protocol Number MO4002) by the Faculty of Medicine, University of Calgary Animal Welfare Committee and were performed according to the Guidelines published by the Canadian Council on Animal Care, (Vol. 1, 2nd ed.). Human SAP-tg mice ( $n=4-6$ animals per group) were intravenously injected with a lethal dose $\left(\mathrm{LD}_{100} 20 \mathrm{ng} / \mathrm{g}\right.$ of body weight) of Stx1 that was premixed in a total volume of $100 \mu \mathrm{L}$ with a heterobifunctional inhibitor in physiological saline solution. Forty-eight $\mathrm{h}$ after challenge, the mice were monitored every $4 \mathrm{~h}$ and immediately euthanized by $\mathrm{CO}_{2}$ asphyxia if signs of Shigatoxemia (lethargy) became apparent. On the 10th day, all surviving mice were euthanized.

\section{Results and Discussion}

\subsection{Synthesis of Heterobivalent Polymers}

Reaction of the $p$-nitrophenylcarbonate derivative of lactose 2 [11] with amine derived from Boc-protected linker $\mathbf{1}$ provided protected lactose intermediate $\mathbf{3}$ with a linker armed with a terminal alkyne residue. After deprotection and subsequent enzymatic glycosylation of $\mathbf{4}$ the heterobifuntional ligand 5 was obtained (Scheme 1).

Scheme 1. Synthesis of the Type A pendant ligand 5.
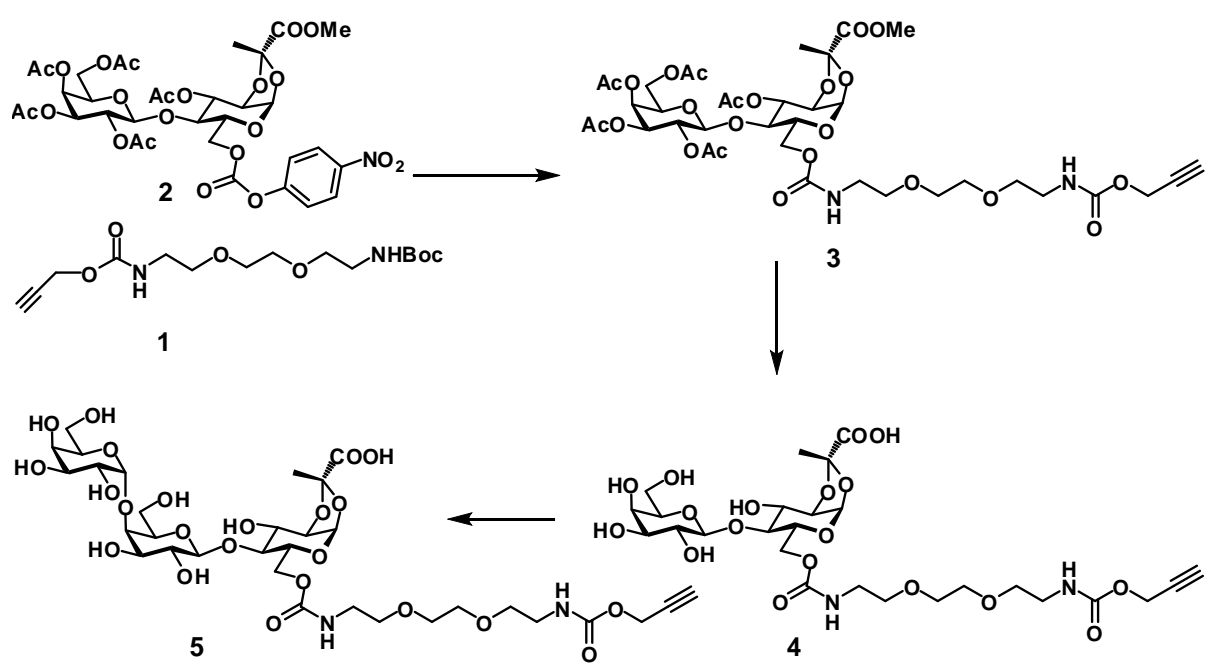

The synthesis of two other heterobifunctional ligands 13 and 17 started with opening of the oxirane ring in cyclic pyruvate derivative 6 with sodium azide (Scheme 2). The resulting alcohol 7 was 
glycosylated with lactose donor $\mathbf{8}$. Reduction of azide $\mathbf{9}$ followed by acetylation gave 10, which was $N$ and $O$-deacetylated with $\mathrm{NaOH}$ solution to give amine 11. Acylation of the amino group in 11 with propargyl chloroformate gave carbamate derivative 12, which was enzymatically $\alpha$-galactosylated to give the desired ligand $\mathbf{1 3}$ ready for conjugation to a polymer. The enzymatic synthesis was previously described and employs a fusion protein that incorporates gluco-galacto epimerase and $\alpha$-1,4-galactosyltransferase activities. This allows the use of the relatively cheap UDP-glucose donor to achieve the introduction of the terminal $\alpha$-galactopyranosyl residue. Analogously, ligand $\mathbf{1 7}$ with a longer linker was obtained by first acylating $\mathbf{1 1}$ with activated carbonate $\mathbf{1 5}$ then enzymatically processing the disaccharide with attached tether $\mathbf{1 6}$ to give $\mathbf{1 7}$.

Scheme 2. Synthesis of the Type B pendant ligands 13 and 17.

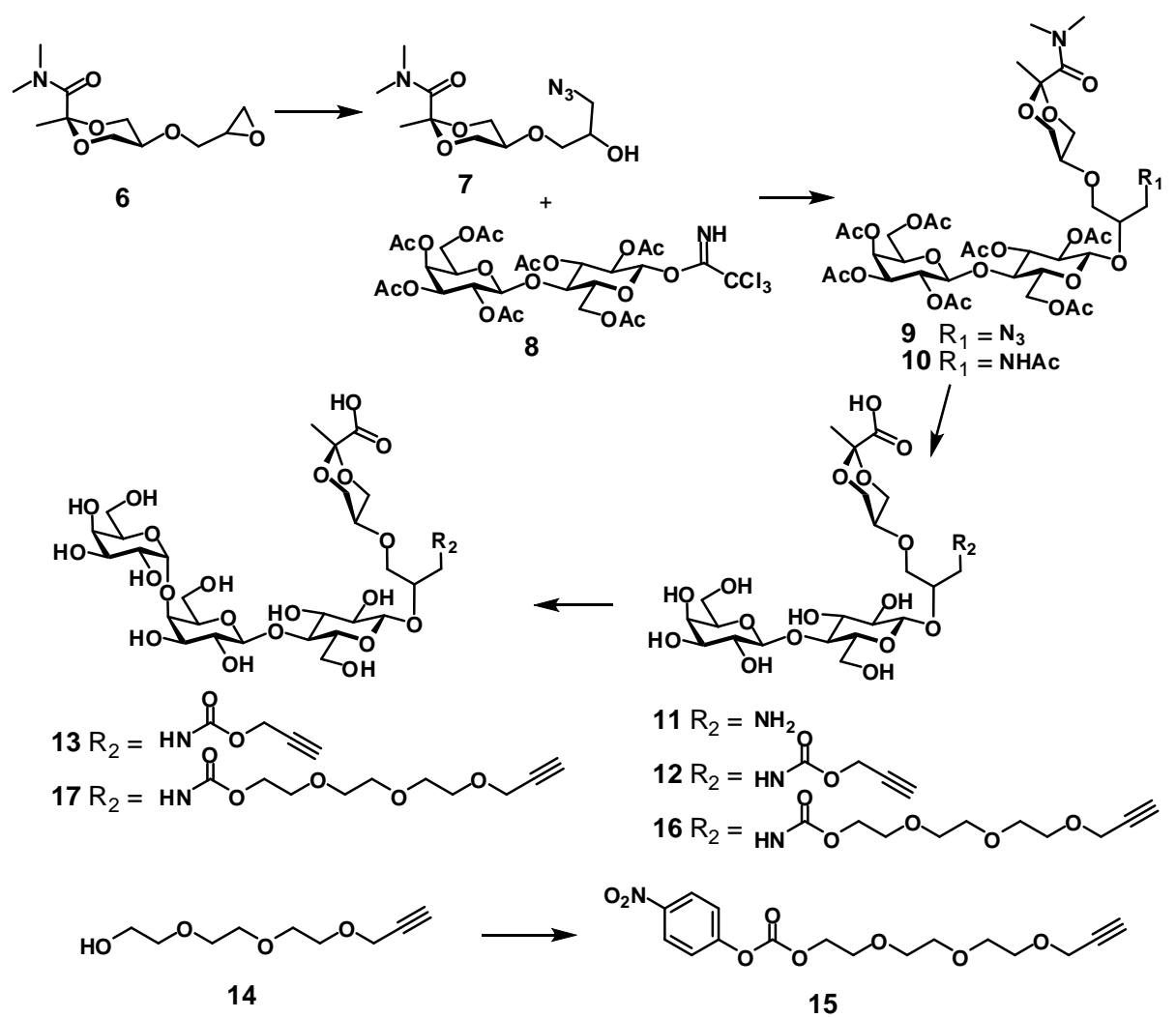

The first set of polymeric ligands was obtained by sequential elongation of the side chain linker in a single batch of co-polymer between $N$-(2-hydroxypropyl) methacrylamide (18, HPMA) and $\mathrm{N}$-(3-tert-butoxycarbonylaminoxypropyl) methacrylamide (19) with cysteamine hydrochloride as a radical initiator. After deprotection of the product of polymerization, the HPMA polymer 20 randomly decorated with amino groups reacted with linker $\mathbf{2 1}$ to provide after deprotection polymer $\mathbf{2 2}$ with elongated side chains. The procedure was repeated to afford polymer $\mathbf{2 3}$ with twice elongated side chains (Scheme 3). The heterobifunctional pendant ligand was installed into the three homologous polymeric scaffolds 20, 21 and $\mathbf{2 2}$ in two steps: first, amino groups in each polymer were coupled with the lactose pyruvate derivative 2 to provide after deacetylation the respective polymers $\mathbf{2 4}, \mathbf{2 5}$ and $\mathbf{2 6}$, each of which were enzymatically galactosylated to provide final products HPMA-n0, HPMA-n1 and HPMA-n2 correspondingly. 
Scheme 3. Synthesis of HPMA conjugates (Type A) by sequential extension of the linker-arm.
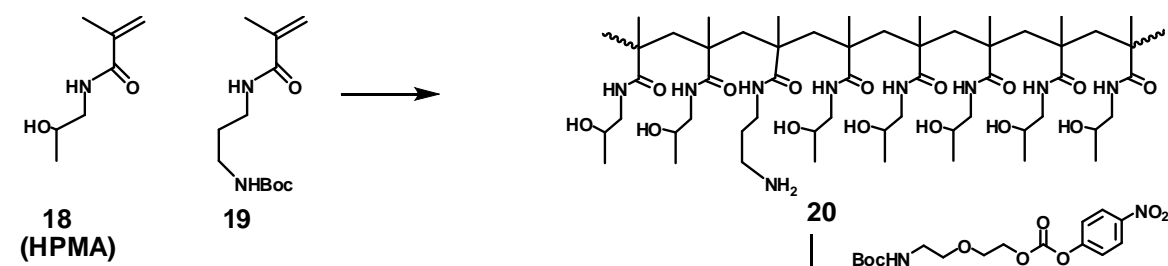

(HPMA)
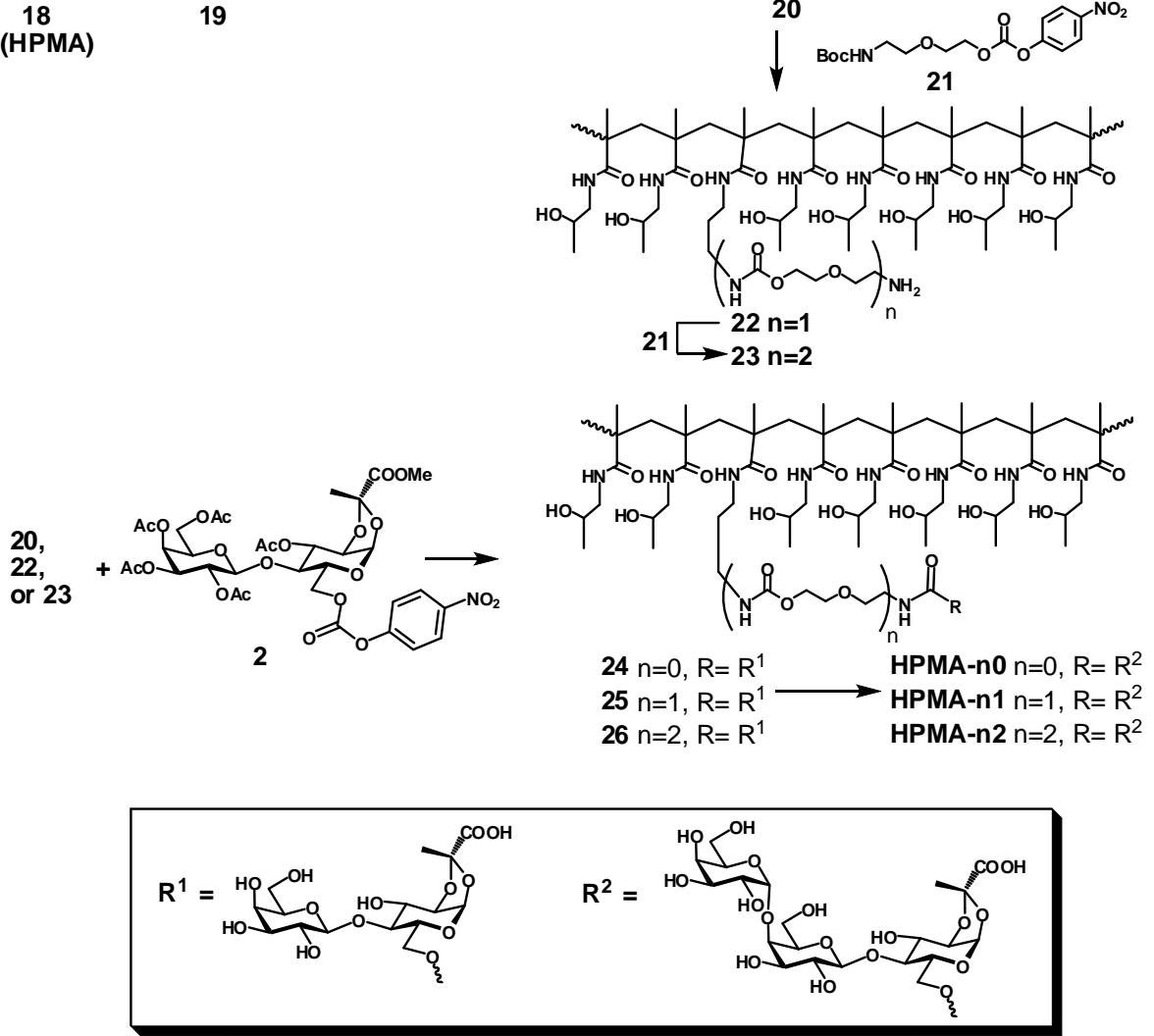

In order to assess influence of polymer size on the activity of heterobifunctional ligands the synthesis of polymeric scaffolds with randomly incorporated azide functionality and different molecular weight was performed by the reversible addition-fragmentation chain transfer process (RAFT). The RAFT copolymerization of HPMA with azide containing methacrylamide monomer (AzMA) was performed in aqueous conditions using 4,4'-azobis(4-cyanovaleric acid) as the initiator and 4-cyanopentanoic acid 4-dithiobenzoate as the chain transfer agent (Scheme 4, Table 1). Two polyacrylamide analogs PAA-27/5 PAA-72/5 with defined molecular weight were obtained by copolymerization of acrylamide with 3-aminopropylmethacrylamide hydrochloride followed by azidination of amino group side chains using azidotransfer reagent, imidazole-1-sulfonyl azide [17].

The conjugation of the heterobifunctional ligands 5, 13 and 17 to the azide-presenting scaffolds was accomplished via an efficient click reaction providing an array of polymeric heterobifunctional ligands: HPMA-16/5-A, HPMA-44/5-A, HPMA-35/10-A, HPMA-20/15-A, HPMA-37/15-A, HPMA-44/5-B, HPMA-35/10-B, HPMA-44/5-C, and HPMA-35/10-C, PAA-27/5-A, PAA-72/5-A. 
Scheme 4. Synthesis of HPMA conjugates (Types A, B and C) with narrow molecular weight distribution by RAFT polymerization.
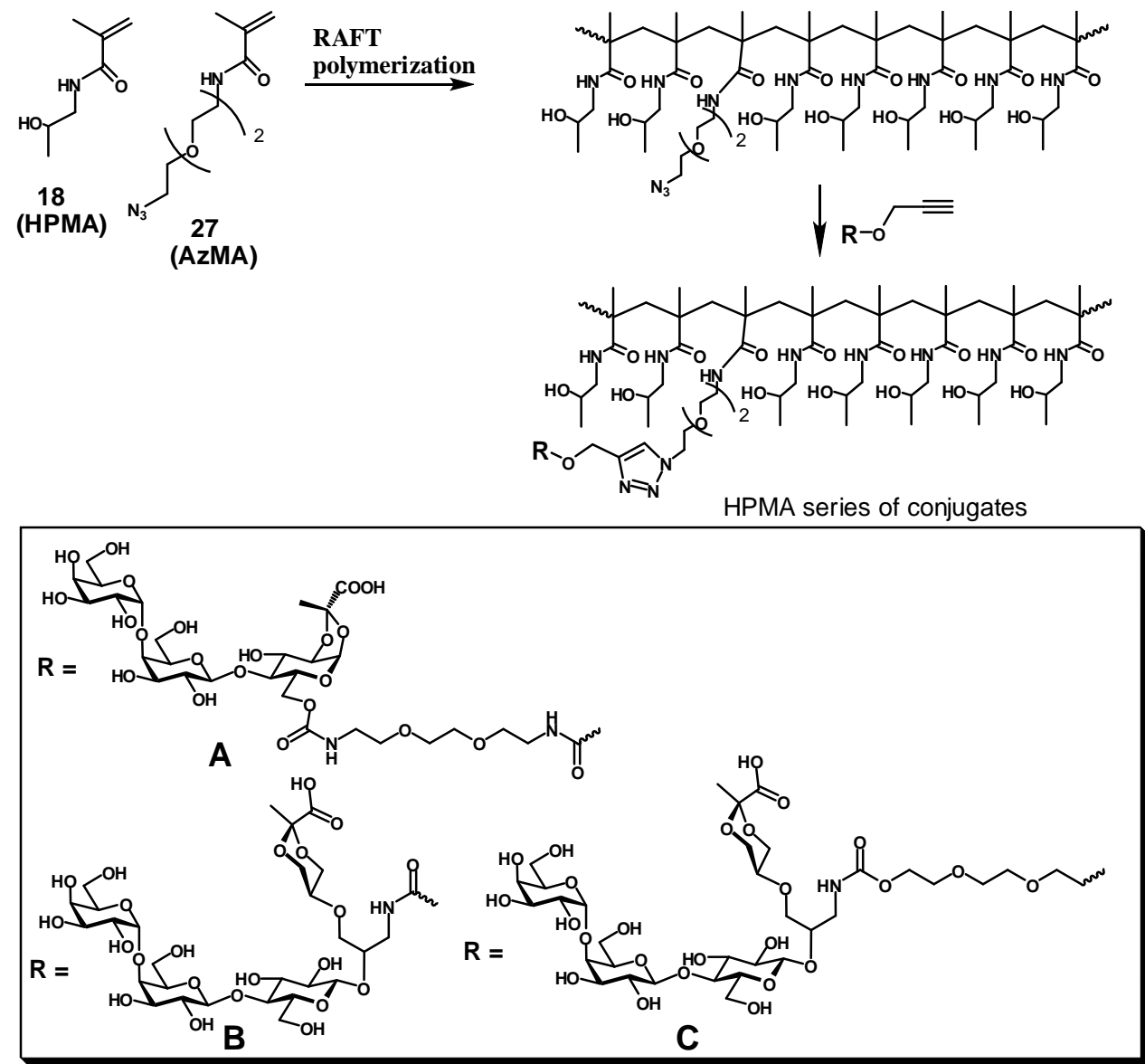

Table 1. Polymeric scaffolds obtained by RAFT polymerization.

\begin{tabular}{llll}
\hline Polymer $^{\text {a }}$ & Molecular Weight, Da & $\mathrm{M}_{\mathrm{w}} / \mathrm{M}_{\mathrm{n}}$ & AzMA substitution, \% \\
\hline HPMA-16/5 & 15900 & 1.34 & 5 \\
HPMA-44/5 & 43600 & 1.35 & 5 \\
HPMA-35/10 & 35100 & 1.34 & 10 \\
HPMA-20/15 & 19500 & 1.32 & 15 \\
HPMA-37/15 & 36700 & 1.41 & 15 \\
PAA-27/5 & 27000 & 1.29 & 5 \\
PAA-72/5 & 72000 & 1.38 & 5 \\
\hline
\end{tabular}

${ }^{\mathrm{a}}$ polymers are named according to the principle monomer; the indices indicate molecular weight in $\mathrm{kDa}$ and $\%$ substitution with azide monomer AzMA. 
Scheme 5. Synthesis of PAA conjugates (Type A) with narrow molecular weight distribution by RAFT polymerization.

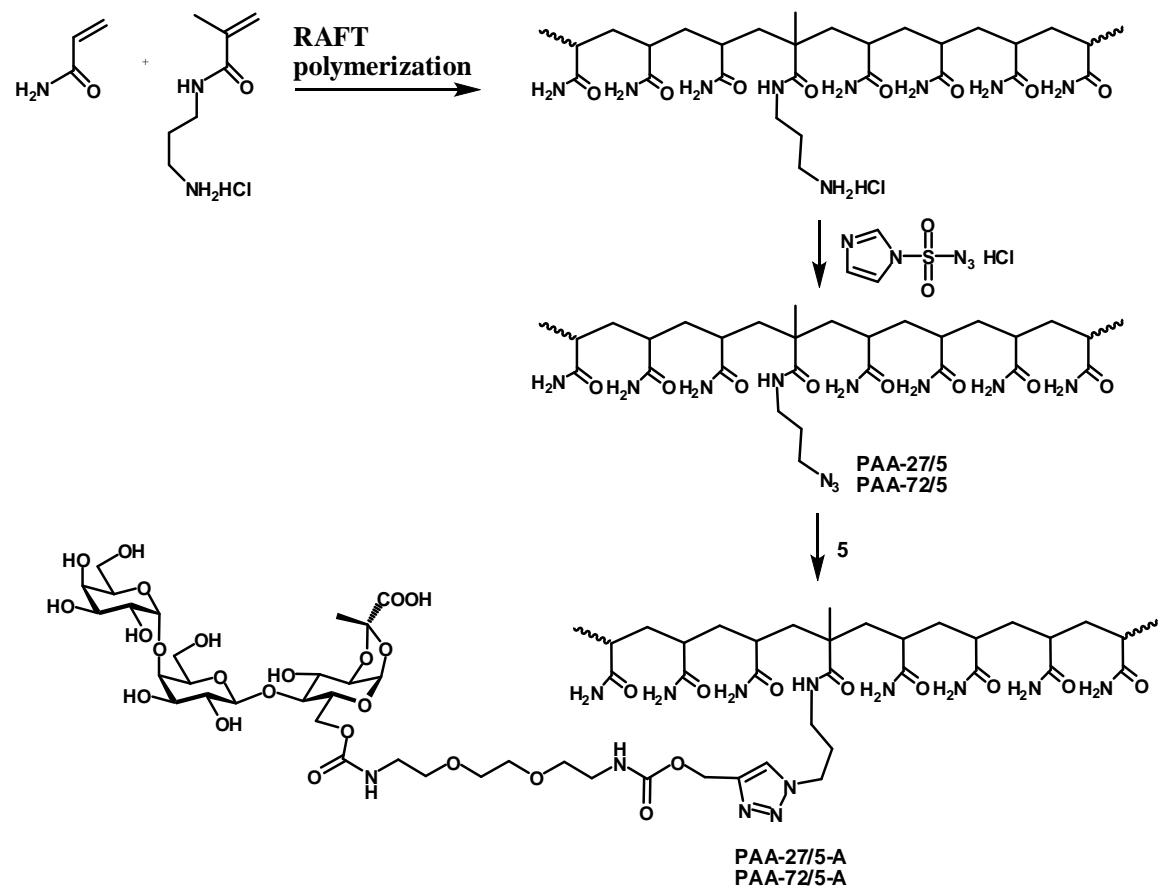

\subsection{Evaluation of Inhibitory Activity}

Supramolecular inhibition is a novel strategy for the design of antagonists for pathogenic agents. The approach takes advantage of an endogenous protein such as an antibody or serum proteins of the innate immune system that serve as a template for presentation of a binding moiety specific to the target protein or cell [22-26]. In addition to providing a pre-organized scaffold and enhancing activity due to the multivalency effect the templating protein can function as an effector which initiates attack by the immune system or redirects the bound species away from susceptible organs. Thus, PolyBAIT-mediated interaction with SAP results in re-routing of Stx 1 from kidney to the spleen and liver, where the toxin can be safely disposed [11].

In order to address the feasibility of using polymeric heterobifunctional inhibitors such as PolyBAIT as injectable drugs to treat patients infected with enterohemorrhagic E. coli two main issues have to be resolved, namely, replacing polyacrylamide with a more biocompatible polymer, and controlling the molecular weight of the polymer-carrier to be below the kidney excretion cut-off. As the polyacrylamide backbone replacement we chose $N$-(2-hydroxypropyl)methacryamide (HPMA). Since its original use as a blood plasma expander [27,28]. HPMA is the most extensively studied soluble polymer with a nondegradable backbone, which itself or as a copolymer have been employed in a broad variety of biomedical applications ranging from immunosuppressives, vaccines, cancerostatic drugs, imaging agents and targeting of gene delivery vectors [29].

Preliminary evaluation of the feasibility of replacing acrylamide as the polymeric backbone in PolyBAITs was performed on a series of homologous polymeric inhibitors HPMA-n0, HPMA-n1 and HPMA-n2. These differed only in the length of the spacer-arm and were identical in all other respects since all of them were prepared from the same batch of aminated polyHPMA by sequential elongation of the linker. Inhibition data for both solid phase assay and cell intoxication assay presented in Figure 
2A and Figure 2B revealed a trend of increasing activity with elongation of the spacer. Additionally, direct correspondence between activities in both assays was in sharp contrast with other multivalent inhibitors, for which we previously observed significant reduction of activity upon transition from ELISA to cytotoxicity assays. At the same time, the inhibitory power of the highest activity conjugate HPMA-n2 was still an order of magnitude lower than that of original polyacrylamide-based PolyBAIT (Table 2).

Conjugate HPMA-n2 was tested in vivo for its ability to prevent intoxication of transgenic mice, which express human SAP at levels similar to humans ( $20-60 \mathrm{mg} / \mathrm{L})$. At the concentration, which was sufficient for the original PolyBAIT preparation to completely protect mice from the effects of Stx1 (200 $\mu \mathrm{g} /$ mouse), administration of HPMA-n2 resulted in 10-20 h delay of symptom onset, while complete protection was achieved at a 3 fold higher dose (Figure 2C). Again, lower inhibitory activity in the solid-phase and cytotoxicity assays directly translated into reduced efficacy in vivo (compare original PolyBAIT and HPMA-n2). This result confirmed the human SAP-dependant protective properties of tailored heterobifunctional polymers and the feasibility of transition of the methodology to a different polymer-carrier. Influences of length of the linker on the activity of the heterobifunctional polymer both in ELISA and cell culture assays suggest greater interference of the scaffold in HPMA polymers with formation of a supramolecular complex as compared with less bulky side chains in polyacrylamide. However, the question of how the nature of the polymer-carrier and its variable parameters such as molecular weight and payload influence the activity remained to be addressed.

Reversible addition-fragmentation chain transfer (RAFT) polymerization have previously been successfully employed to prepare HPMA copolymers with polydispersity of 1.1-1.8 (depending on molecular weight) containing methacrylamide monomers with a reactive group or cargo drug [30-32]. Such well defined copolymers with a narrow molecular weight range are the best candidates for in vivo and clinical testing of polymeric therapeutical and diagnostic agents. In the present work, we took advantage of the highly efficient "click reaction", which enables conjugation of the active component to a polymer in aqueous media. The azido group of the AzMA monomer incorporated into HPMA backbone served as a reactive functionality, which permited nearly quantitative conjugation of carbohydrate ligands.

Evaluation of a series of defined molecular weight heterobifunctional inhibitors was conducted in solid-phase ELISA assay (Table 2). Surprisingly, with the exception of polymer HPMA-16/5-A with the lowest molecular weight, all compounds of the HPMA series have shown very similar activities regardless of molecular weight and also regardless of the payload (percent incorporation) of the binding fragments. Furthermore, in the case of ligands containing spatially separated binding fragments in each pendant grouping (polymers of types B and C Scheme 4), elongation of the linker did not influence activity at all in sharp contrast with the fused analogs as discussed above. Noteworthy, in both HMPA and polyacrylamide series, increase of effective concentration of pendant heterobifunctional ligand either by increasing payload or size of the polymer was counterproductive: even if the effective dose remained the same the activity per pendant ligand reduced with increase of size and payload. The optimal activity could be achieved at relatively low payload and incorporation degree. 
Figure 2. Biological evaluation of HPMA-based heterobifunctional inhibitors of Stx 1 . Panel A: inhibition of Stx1 binding to Gb3 analog-coated microtiter plates; Panel B: inhibition of intoxication of Vero cells with Stx $1\left(\mathrm{LD}_{100} 25 \mathrm{ng} / \mathrm{mL}\right)$; Panel C: protection of from intoxication with Stx1 at LD100. Survival plot demonstrating the efficacy of HPMA-n2 compared with the original PolyBAIT in preventing Stx1-mediated lethality in human SAP-transgenic mice. Mice received a single anterior dorsal injection of a lethal dose of Stx1 (LD $10020 \mathrm{ng} / \mathrm{g}$ of body weight) that was premixed with a heterobifunctional inhibitor.
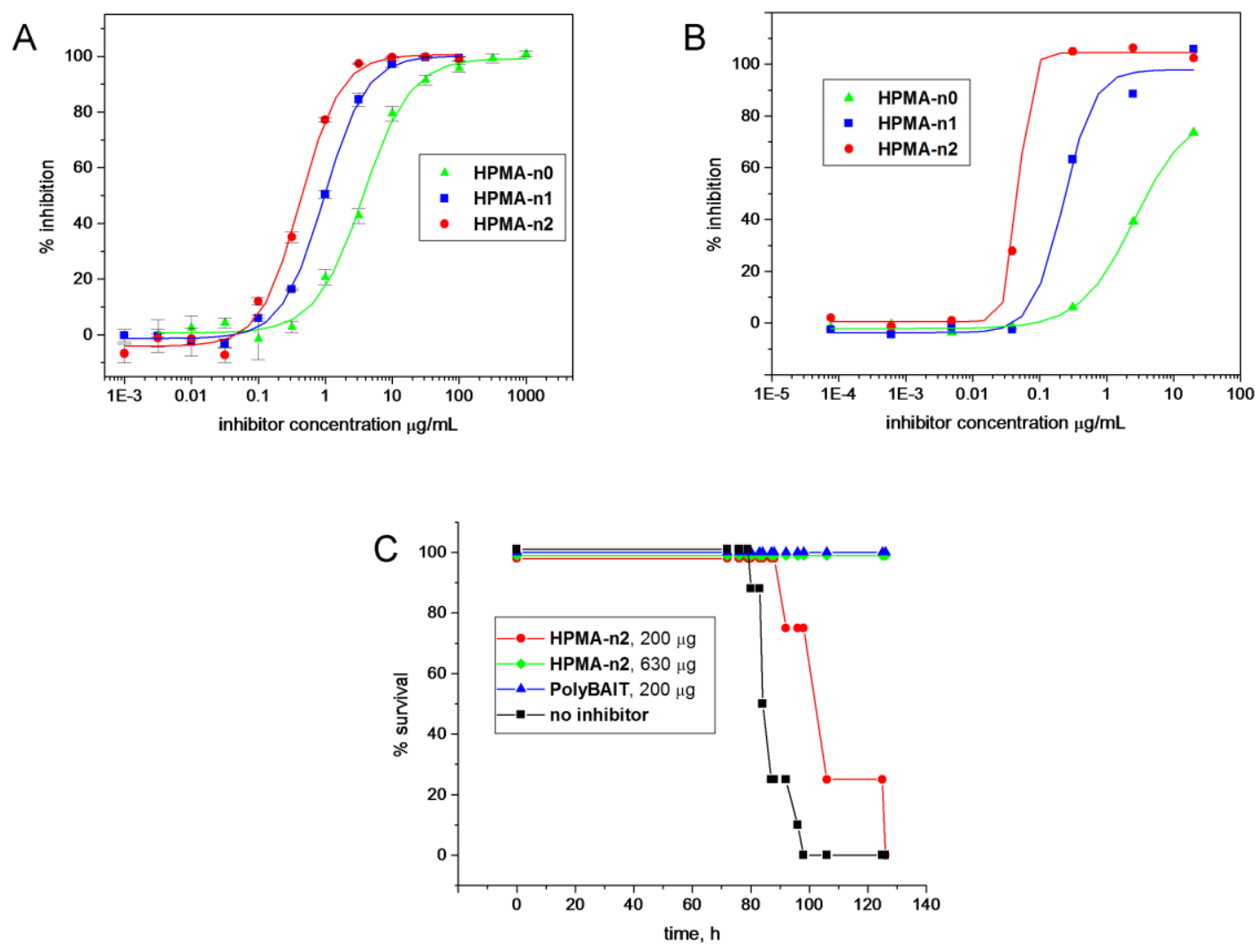

The crystal structure of Stx1 in complex with $\mathrm{P}^{\mathrm{k}}$-trisaccharide [33] revealed three distinct $\mathrm{P}^{\mathrm{k}}$-trisaccharide binding sites per B-subunit, of which site 2 has been shown to have the highest affinity [34]. Glucose moieties at the reducing end of bound $\mathrm{P}^{\mathrm{k}}$-trisaccharides for site 1 and site 2 are located at approximately the same distance from the center pore of the B-pentamer and both are sufficient to span the distance between center pore of SAP and bound pyruvate ligand. However, when pyruvate is fused to glucose moiety (pendant ligand type A), only binding to site 2 provides the correct presentation of the pyruvate moiety to SAP. Site 3 is located too close the center pore and a heterobifunctional ligand would be unable to engage both proteins simultaneously at more than one or two points. Correct presentation of $\mathrm{P}^{\mathrm{k}}$-trisaccharide as a part of $\mathrm{Gb}_{3}$ glycolipid has recently been shown to play an important role in the interaction of Stx1 with the cell surface [35]. Hence, only binding at site 2 was considered in our design of pendant heterobifunctional ligands. A molecular model of the ternary complex mediated by a fused version of the heterobifunctional ligand (Figure 1) suggests that the exact alignment and orientation of each binding fragment to its respective protein should result in very close protein-to-protein contact leaving no space for a linker or polymeric scaffold. It is, 
therefore, unlikely that the scaffolding polymer and the linker occupy the space between Stx and SAP. Furthermore, when the trisaccharide is bound to Stx, the pyruvate moiety is now presented $\sim 1.5-2 \AA$ further toward the periphery and not exactly in register with the pyruvate-binding site on the SAP surface. Assembly of the ternary complex may require conformational distortions in the separate heterobifunctional ligands and entail entropic penalties. As a trade-off, the small gap between the multimeric receptors introduced by the short spacer in polymers of types B and C brings about easier passage of the scaffolding polymer between proteins and increases the number of possible microscopic complexes. Such additional freedom can add a favorable combinatorial entropy term to the binding free energy [36]. The optimum length of the spacer can probably be found for a particular supramolecular assembly.

Table 2. Activities of PolyBAITs.

\begin{tabular}{|c|c|c|c|c|c|}
\hline Polymer & Pendant Ligand Type & Linker & Payload, \% & $\mathrm{IC}_{50}, \mu \mathrm{g} / \mathrm{mL}$ & $\mathrm{IC}_{50}, \mu \mathrm{M}^{\mathrm{a}}$ \\
\hline HPMA-n $^{\text {b }}$ & Fused & Short & 5 & 3.7 & 1.07 \\
\hline HPMA-n1 & Fused & Long & 5 & 0.98 & 0.27 \\
\hline HPMA-n2 & Fused & Extra long & 5 & 0.45 & 0.12 \\
\hline HPMA-16/5-A ${ }^{c}$ & Fused & Long & 5 & 1.2 & 0.32 \\
\hline HPMA-44/5-A & Fused & Long & 5 & 0.22 & 0.06 \\
\hline HPMA-35/10-A & Fused & Long & 10 & 0.25 & 0.11 \\
\hline HPMA-20/15-A & Fused & Long & 15 & 0.24 & 0.13 \\
\hline HPMA-37/15-A & Fused & Long & 15 & 0.19 & 0.106 \\
\hline HPMA-44/5-B & Separate & Short & 5 & 0.35 & 0.095 \\
\hline HPMA-35/10-B & Separate & Short & 10 & 0.29 & 0.13 \\
\hline HPMA-44/5-C & Separate & Long & 5 & 0.27 & 0.07 \\
\hline HPMA-35/10-C & Separate & Long & 10 & 0.28 & 0.12 \\
\hline PAA-27/5-A & Fused & Long & 5 & 0.019 & 0.008 \\
\hline PAA-72/5-A & Fused & Long & 5 & 0.046 & 0.019 \\
\hline
\end{tabular}

${ }^{\mathrm{a}}$ based on pendant ligand; ${ }^{\mathrm{b}}$ this and the following polymers are named according to the principle monomer followed by the number of extension linkers holding pendant ligand; ${ }^{c}$ this and the following polymers are named according to the principle monomer; indices show molecular weight in $\mathrm{kDa} \% \%$ substitution with pendant ligands and type of conjugated unimeric ligand.

\section{Conclusions}

In summary, we have synthesized and evaluated a series of HPMA-based PolyBAITs, polymeric heterobifunctional ligands that inhibit Stx1 in a SAP-dependent manner. We observed that the inhibitory power of PolyBAITs in a solid-phase assay correlates with the cytotoxicity assay and efficacy in vivo. We demonstrate that the inhibition is moderately influenced by the structure of the pendant ligand and the length of the spacer but is practically independent of molecular weight and the polymer density of the glycans. Our results suggest that steric bulk of the side chains in the polymeric scaffold impedes assembly of a supramolecular complex with endogenous serum protein SAP and requires heterobifunctional ligands that allow for greater separation between specific binding fragments. 


\section{Acknowledgments}

We thank Wakarchuk, W.W.; NRC, Ottawa, for generous gift of $\alpha$-1,4-galactosyltransferase/ UDP-4'-Gal-epimerase fusion enzyme and the Alberta Innovates Centre for Carbohydrate Science for funding. TPG was the recipient of an NSERC Canada Graduate Scholarship.

\section{References}

1. Griffin, P.M. Escherichia coli O157:H7 and Other Enterohemorrhagic Escherichia coli. In Infections of the gastrointestinal tract; Raven Press: Newyork, UK, USA, 1995, pp. 739-761.

2. Karch, H.; Tarr, P.I.; Blelaszewska, M. Enterohaemorrhagic Escherichia coli in human medicine. Int. J. Med. Microbiol. 2005, 295, 405-418.

3. Wong, C.S.; Jelacic, S.; Habeeb, R.L.; Watkins, S.L.; Tarr, P.I. The risk of the hemolytic-uremic syndrome after antibiotic treatment of Escherichia coli O157: H7 infections. N. Engl. J. Med. 2000, 342, 1930-1936.

4. Dundas, S.; Todd, W.T.A.; Stewart, A.I.; Murdoch, P.S.; Chaudhuri, A.K.R.; Hutchinson, S.J. The central Scotland Escherichia coli O157: H7 outbreak: Risk factors for the hemolytic uremic syndrome and death among hospitalized patients. Clin. Infect. Dis. 2001, 33, 923-931.

5. Trachtman, H.; Cnaan, A.; Christen, E.; Gibbs, K.; Zhao, S.Y.; Acheson, D.W.K.; Weiss, R.; Kaskel, F.J.; Spitzer, A.; Hirschman, G.H. Effect of an oral Shiga toxin-binding agent on diarrhea-associated hemolytic uremic syndrome in children-A randomized controlled trial. J. Am. Med. Assoc. 2003, 290, 1337-1344.

6. Nakao, H.; Kataoka, C.; Kiyokawa, N.; Fujimoto, J.; Yamasaki, S.; Takeda, T. Monoclonal antibody to Shiga toxin 1, which blocks receptor binding and neutralizes cytotoxicity. Microbiol. Immunol. 2002, 46, 777-780.

7. Nakao, H.; Kiyokawa, N.; Fujimoto, J.; Yamasaki, S.; Takeda, T. Monoclonal antibody to Shiga toxin 2 which blocks receptor binding and neutralizes cytotoxicity. Infect. Immun. 1999, 67, 5717-5722.

8. Lopez, E.L.; Contrini, M.M.; Glatstein, E.; Ayala, S.G.; Santoro, R.; Allende, D.; Ezcurra, G.; Teplitz, E.; Koyama, T.; Matsumoto, Y.; Sato, H.; Sakai, K.; Hoshide, S.; Komoriya, K.; Morita, T.; Harning, R.; Brookman, S. Safety and pharmacokinetics of urtoxazumab, a humanized monoclonal antibody, against Shiga-like toxin 2 in healthy adults and in pediatric patients infected with Shiga-like toxin-producing Escherichia coli. Antimicrob. Agents Chemother. 2010, 54, 239-243.

9. Nishikawa, K. Recent progress of Shiga toxin neutralizer for treatment of infections by Shiga toxin-producing Escherichia coli. Arch. Immunol. Ther. Exp. (Warsz) 2011, 59, 239-247.

10. Stechmann, B.; Bai, S.-K.; Gobbo, E.; Lopez, R.; Merer, G.; Pinchard, S.; Panigai, L.; Tenza, D.; Raposo, G.; Beaumelle, B.; Sauvaire, D.; Gillet, D.; Johannes, L.; Barbier, J. Inhibition of retrograde transport protects mice from lethal ricin challenge. Cell 2010, 141, 231-242.

11. Kitov, P.; Mulvey, G.; Griener, T.; Lipinski, T.; Solomon, D.; Paszkiewicz, E.; Jacobson, J.; Sadowska, J.; Suzuki, M.; Yamamura, K.; Armstrong, G.; Bundle, D. In vivo supramolecular 
templating enhances the activity of multivalent ligands: A potential therapeutic against the Escherichia coli O157 AB(5) toxins. Proc. Natl. Acad. Sci. USA 2008, 105, 16837-16842.

12. Suzuki, T.; Hisakawa, S.; Itoh, Y.; Suzuki, N.; Takahashi, K.; Kawahata, M.; Yamaguchi, K.; Nakagawa, H.; Miyata, N. Design, synthesis, and biological activity of folate receptor-targeted prodrugs of thiolate histone deacetylase inhibitors. Bioorg. Med. Chem. Lett. 2007, 17, 4208-4212.

13. Solomon, D.; Kitov, P.I.; Paszkiewicz, E.; Grant, G.A.; Sadowska, J.M.; Bundle, D.R. Heterobifunctional multivalent inhibitor-adaptor mediates specific aggregation between Shiga toxin and a pentraxin. Org. Lett. 2005, 7, 4369-4372.

14. Li, H.; Li, Q.; Cai, M.; Li, Z. Synthesis of galactosyl and lactosyl derivatives as potential anti-metastasis compounds. Carbohydr. Res. 2000, 328, 611-615.

15. Lu, G.; Lam, S.; Burgess, K. An iterative route to "decorated" ethylene glycol-based linkers. Chem. Commun. 2006, 1652-1654.

16. Klein, E.; DeBonis, S.; Thiede, B.; Skoufias, D.; Kozielski, F.; Lebeau, L. New chemical tools for investigating human mitotic kinesin Eg5. Bioorg. Med. Chem. 2007, 15, 6474-6488.

17. Goddard-Borger, E.D.; Stick, R.V. An efficient, inexpensive, and shelf-stable diazotransfer reagent: Imidazole-1-sulfonyl azide hydrochloride. Org. Lett. 2011, 13, 2514-2514;

18. Kitov, P.; Sadowska, J.; Mulvey, G.; Armstrong, G.; Ling, H.; Pannu, N.; Read, R.; Bundle, D. Shiga-like toxins are neutralized by tailored multivalent carbohydrate ligands. Nature 2000, 403, 669-672.

19. Kitov, P.; Lipinski, T.; Paszkiewicz, E.; Solomon, D.; Sadowska, J.; Grant, G.; Mulvey, G.; Kitova, E.; Klassen, J.; Armstrong, G.; Bundle, D. An entropically efficient supramolecular inhibition strategy for Shiga toxins. Angew. Chem. Inter. Ed. 2008, 47, 672-676.

20. Zhao, X.; Araki, K.; Miyazaki, J.; Yamamura, K. Developmental and liver-specific expression directed by the serum amyloid-p component promoter in transgenic mice. J. Biochem. 1992, 111, 736-738.

21. Kitov, P.I.; Paszkiewicz, E.; Wakarchuk, W.W.; Bundle, D.R. Preparative-scale chemoenzymatic synthesis of large carbohydrate assemblies using alpha(1-4)galactosyltransferase/UDP-4'-Galepimerase fusion protein. in Recognition of Carbohydrates in Biological Systems Pt a: General Procedures 2003, 362, 86-105.

22. Gestwicki, J.E.; Crabtree, G.R.; Graef, I.A. Harnessing chaperones to generate small-molecule inhibitors of amyloid beta aggregation. Science 2004, 306, 865-869.

23. Bertozzi, C.R.; Bednarski, M.D. Antibody targeting to bacterial-cells using receptor-specific ligands. J. Am. Chem. Soc. 1992, 114, 2242-2245.

24. Shokat, K.M.; Schultz, P.G. Redirecting the immune-response - ligand-mediated immunogenicity. J. Am. Chem. Soc. 1991, 113, 1861-1862.

25. O’Reilly, M.K.; Collins, B.E.; Han, S.; Liao, L.; Rillahan, C.; Kitov, P.I.; Bundle, D.R.; Paulson, J.C. Bifunctional CD22 ligands use multimeric immunoglobulins as protein scaffolds in assembly of immune complexes on B cells. J. Am. Chem. Soc. 2008, 130, 7736-7745.

26. Cui, L.; Kitov, P.I.; Completo, G.C.; Paulson, J.C.; Bundle, D.R. Supramolecular complexing of membane siglec CD22 mediated by a polyvalent heterobifunctional ligand that templates on IgM. Bioconjugate Chem. 2011, 22, 546-550. 
27. Sprincl, L.; Exner, J.; Sterba, O.; Kopecek, J. New types of synthetic infusion solutions. 3. Elimination and retention of poly $n$-(2-hydroxypropyl)methacrylamide in a test organism. J. Biomed. Mater. Res. 1976, 10, 953-963.

28. Sterba, O.; Uhlirova, Z.; Petz, R.; Viktora, L.; Jirasek, A.; Kopecek, J. Duxon-A new Czechoslovak-made infusion solution-An experimental contribution to biological evaluation. Cas. Lek. Cesk. 1980, 119, 994-997.

29. Ulbrich, K.; Subr, V. Structural and chemical aspects of HPMA copolymers as drug carriers. Adv. Drug Deliv. Rev. 2010, 62, 150-166.

30. Yanjarappa, M.J.; Gujraty, K.V.; Joshi, A.; Saraph, A.; Kane, R.S. Synthesis of copolymers containing an active ester of methacrylic acid by RAFT: Controlled molecular weight scaffolds for biofunctionalization. Biomacromolecules 2006, 7, 1665-1670.

31. Liu, X.M.; Quan, L.D.; Tian, J.; Alnouti, Y.; Fu, K.; Thiele, G.M.; Wang, D. Synthesis and evaluation of a well-defined HPMA copolymer-dexamethasone conjugate for effective treatment of rheumatoid arthritis. Pharm. Res. 2008, 25, 2910-2919.

32. Herth, M.M.; Barz, M.; Moderegger, D.; Allmeroth, M.; Jahn, M.; Thews, O.; Zentel, R.; Rosch, F. Radioactive labeling of defined HPMA-based polymeric structures using F-18 FETos for in vivo imaging by positron emission tomography. Biomacromolecules 2009, 10, 1697-1703.

33. Ling, H.; Boodhoo, A.; Hazes, B.; Cummings, M.D.; Armstrong, G.D.; Brunton, J.L.; Read, R.J. Structure of the Shiga-like toxin I B-pentamer complexed with an analogue of its receptor Gb(3). Biochemistry 1998, 37, 1777-1788.

34. Soltyk, A.M.; MacKenzie, C.R.; Wolski, V.M.; Hirama, T.; Kitov, P.I.; Bundle, D.R.; Brunton, J.L. A mutational analysis of the globotriaosylceramide-binding sites of verotoxin VT1. J. Biol. Chem. 2002, 277, 5351-5359.

35. Lingwood, D.; Binnington, B.; Rog, T.; Vattulainen, I.; Grzybek, M.; Coskun, U.; Lingwood, C.A.; Simons, K. Cholesterol modulates glycolipid conformation and receptor activity. Nature Chem. Biol. 2011, 7, 260-262.

36. Kitov, P.I.; Bundle, D.R. On the nature of the multivalency effect: A thermodynamic model. J. Am. Chem. Soc. 2003, 125, 16271-16284.

(C) 2011 by the authors; licensee MDPI, Basel, Switzerland. This article is an open access article distributed under the terms and conditions of the Creative Commons Attribution license (http://creativecommons.org/licenses/by/3.0/). 